\title{
Crosstalk the Microdialysis in Scientific Research: from Principle to its Applications
}

\author{
Maxwell Kim Kit Lee ${ }^{1,2}$ and Liuqing $\mathrm{Di}^{1,2 *}$
}

${ }^{1}$ School of Pharmacy, Nanjing University of Chinese Medicine, 138, Xianlin Street, Nanjing,210046, PR China

${ }^{2}$ Jiangsu Engineering Research Center for Efficient Delivery System of Traditional Chinese Medicine, Nanjing, PR China

\begin{abstract}
The microdialysis technique is an invasive, expensive and a new real-time continuous in vivo sampling technique. The microdialysis technique with high sensitivity, good selectivity of modern analytical techniques combined with truly online real-time in vivo determination of the endogenous substances and drugs, which can effectively shorten the sampling time and increase the sample stability, can save time and cost savings and improve time resolution to accurately observe the rapid changes that are a major breakthrough in vivo drug analysis. When considering the need for on-line coupled with analysis of microdialysis, the probe recovery, perfusion rate, relative molecular weight analytes, such as the impact on the recovery of the probe, as well as analysis requires sample volume, analytes concentration range, the methods of the sample and related factors limit of quantification, analysis speed and others. In the recent years, the microdialysis technique is applied in all the fields such as the brain, blood, skin and others. But however, this technology itself also has some limitations such as the determination of oil-water partition coefficient greater drug determination, low levels content of drugs determination, the probes implanted reproducibility and other problems. In this review, we would like to focus on the microdialysis technique principles, its advantages and limitations, the each type of the microdialysis probes, the microdialysis technique quantitative factors, the application on the brain, blood, eye, pharmacokinetic, distribution study and others, and the microdialysis technique on-line coupled to the modern analysis technology.
\end{abstract}

Keywords: Microdialysis technique; Probe recovery; Perfusion rate

\section{Introduction}

The microdialysis technique is quite similar to the artificial vascular microdialysis probe implanted into the mining sample site. This technique can be carried out through the probe membrane concentration inside and outside the errand that is sampled material with a concentration gradient degree within the probe by passive diffusion, so as the perfusate can be continuously taken out to achieve the in vivo sampling propose. The microdialysis technique was initially applied in measuring the endogenous biological substances such as real-time monitoring the neurotransmitters, hormones, glucose and others to assess their biochemical functions in the body (refer to the Figure 1) [1]. Its essence is based on the "membrane sampling" and "membrane separation" technology. The collected sample can be directly analyzed without any pre-treatment. Due to its dual roles of "sampling" and "purified" technology [2], it can significantly reduce the sample pre-treatment errors and variation, thus also reducing the labor intensity. This method meanwhile can help the researchers to obtain the complete concentration-time curve, significant savings in the experimental animals and reduce the animal welfare organizations stress and ethics constraints.

In the past decade, in clinical practice, the microdialysis technology remains a research tool, and according to the available guidelines

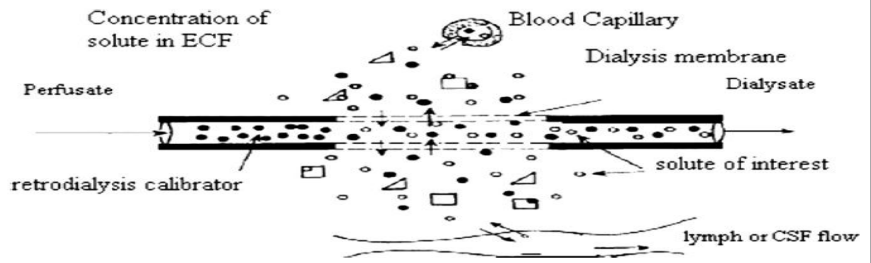

Figure 1: Depicteda schematic flow diagram of the microdialysis technique process.
$\mathrm{MD}$ is currently widely implemented only in brain injury, where this technique helps in understanding pathophysiology, in therapeutic target selection and in prognostication. Of importance, in this setting MD detects metabolic events before these are evident in blood. This technology has become an important neuroscience research [3-7]. In the recent years, its advantages are very prominent in the life science research and more widespread applied in the pharmacokinetic studies especially in the field of the drugs distribution and metabolism studies. This microdialysis method requires a microdialysis probe to mimic a blood capillary and a shaft covering with a semipermeable hollow fiber membrane at its tip, which is connected to the inlet and outlet tubing.

\section{The Microdialysis Research Chronological Time Line}

"Microdialysis", MD the term originated in the late 1950s and began to be used until nowadays. According to the past research, the research of microdialysis and the following summary of the microdialysis history and highlights will be performed in the below Table 1.

Even though the microdialyisis technique was an essential tool focusing on the neuroscience field preclinical and clinical studies, but this method could be applied in other areas like there was an initial pilot report in which the MD method was used to assess the intratumoral

${ }^{*}$ Corresponding author: Liuqing $\mathrm{Di}$, School of Pharmacy, Nanjing University of Chinese Medicine, 138 Xianlin Street, Nanjing 210046, PR China, Tel: +86 2585811230; Fax:+86 2583271038; E-mail: diliuqing@hotmail.com

Received November 28, 2013; Accepted December 23, 2013; Published December 28, 2013

Citation: Lee MKK, Di L (2014) Crosstalk the Microdialysis in Scientific Research from Principle to its Applications. Pharm Anal Acta 5: 276. doi: 10.4172/21532435.1000276

Copyright: ( 2013 Lee MKK, et al. This is an open-access article distributed under the terms of the Creative Commons Attribution License, which permits unrestricted use, distribution, and reproduction in any medium, provided the original author and source are credited. 
Citation: Lee MKK, Di L (2014) Crosstalk the Microdialysis in Scientific Research: from Principle to its Applications. Pharm Anal Acta 5: 276. doi: $10.4172 / 2153-2435.1000276$

\begin{tabular}{|l|l|l|}
\hline Year & Scientist & Research \\
\hline 1958 & Kslant & First describing a kind of methods of extracting the polarity of steroids in the blood dialysis. \\
\hline 1961 & Gaddum & $\begin{array}{l}\text { Creating the push-pull type perfusion sampling method and applied for monitoring the brain nerve chemicals [4]. It was widely used in many parts } \\
\text { of the brain neurotransmitters detection. }\end{array}$ \\
\hline 1966 & Bito & $\begin{array}{l}\text { First reported by using the semipermeable membrane to investigate the dog blood plasma and brain of the free amino acids and other liquid } \\
\text { electrolytes for sampling [5]. }\end{array}$ \\
\hline 1972 & $\begin{array}{l}\text { Yale } \\
\text { University, } \\
\text { Delgado }\end{array}$ & $\begin{array}{l}\text { First time using the brain microdialysis push-pull perfusion technique to investigate the neurotransmitter dopamine release from the monkey } \\
\text { brain and this technique is established in the brain microdialysis technology in the neuroscience and brain research field. }\end{array}$ \\
\hline 1974 & Urgestedt & $\begin{array}{l}\text { First time establishing the in vivo microdialysis technology applied in the living animals. } \\
\text { A "hollow fiber"-a diameter 200 300 } \text { um tubular semipermeable membrane was created to improve the dialysate concept. } \\
\text { Conducted the microdialysis technology to investigate the central dopamineneurons release from the rat brain [7]. }\end{array}$ \\
\hline $\begin{array}{l}\text { In the mid } \\
1980 s\end{array}$ & & $\begin{array}{l}\text { This method was widely used in the research on the drug distribution and metabolism of tissue in the body. Recently, it was used in the traditional } \\
\text { Chinese medicine and acupuncture therapeutics. }\end{array}$ \\
\hline
\end{tabular}

Table 1: microdialysis history and highlights.
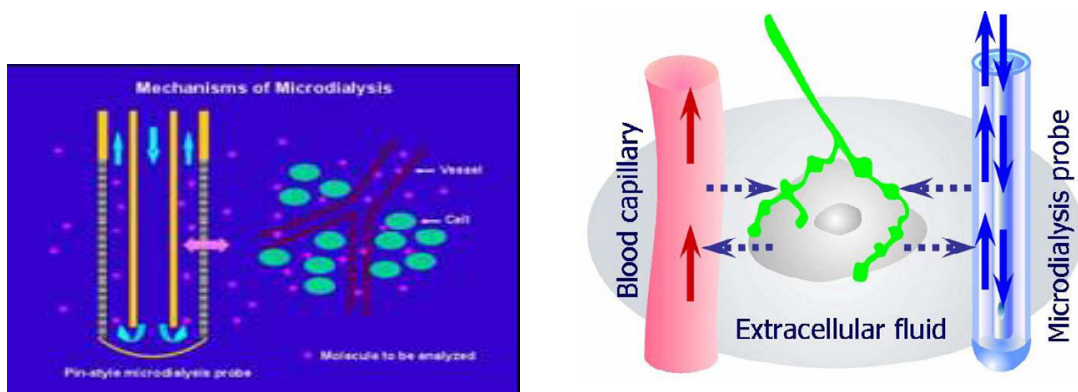

Figure 2: Indicated that the mechanism of microdialysis and the scheme diagram of the probe sampling.

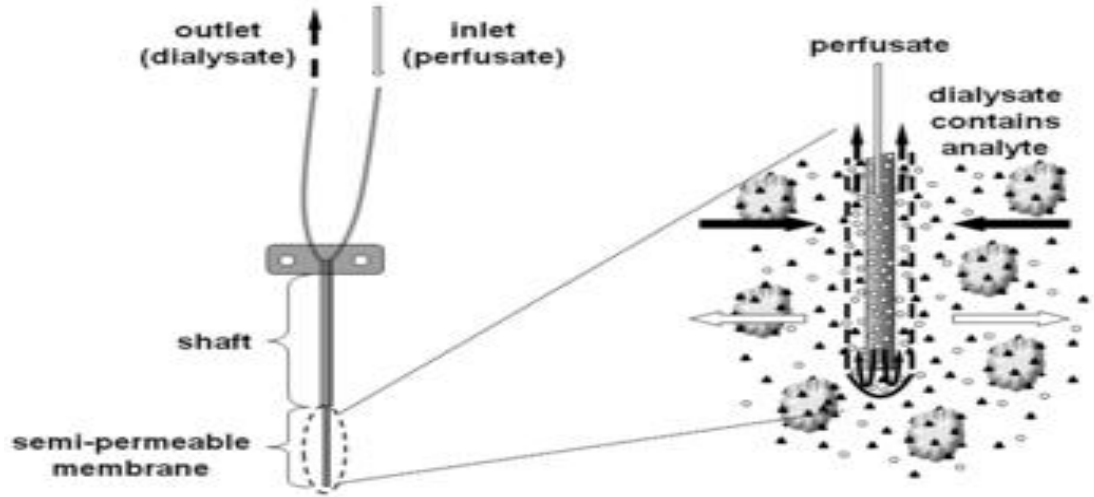

Figure 3: Microdialysis probe schematic diagram.

drug concentrations in vivo in the cancer patients [8]. Apart from that, the MD technique can be also applied in vivo of various human organs and tissues [9] like blood, skin, eye and others. For the example, in 1991, Anderson et al. [10] facilitated the MD method to investigate the ethanol effects in the 7 percutaneous absorption human subjects and firstly proposed the cutaneous microdialysis. In 1998, Cross et al. [11] conducted the MD technique to study the human subjects skin histamine release after the stimulation and was the first time proposed the skin dialysis concept-dermamicrodialysis concept.

Generally the MD technique majority applied in the brain rodent's studies, but as subsequently, the MD technology has become a crucial key in the development of pharmacokinetics studies, especially the drugs distribution and metabolism research. It was found that there were many researchers applied the MD technology to monitor the endogenous metabolite and transmitters levels in the human brain. For the example, Stahle et al. [12] and Hsiao et al. [13] were firstly applied the MD technology in the human pharmacokinetics studies in the 1990s.

\section{The MD Technique Principles}

The MD basic principle is based on the dispersion process. The probe one side is inserted by a catheter into the interstitial space of the tissues in order to achieve the similarity capillary function; the other one side is provided with 2 small tubing, which are inlet tubing and outlet tubing (Figures 2 and 3) [14]. The inlet tubing is connected with the micro-pressure pump, its main function is to maintain the constant low flow to the physiological fluid transport tissue perfusion; while the outlet tubing is connected with the micro-sampler, the micro-sampler 


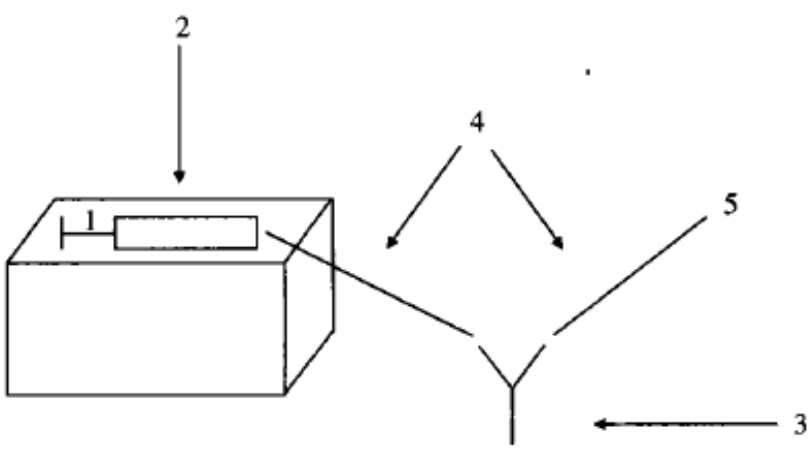

Chart 1: components of the microdiaysis system.

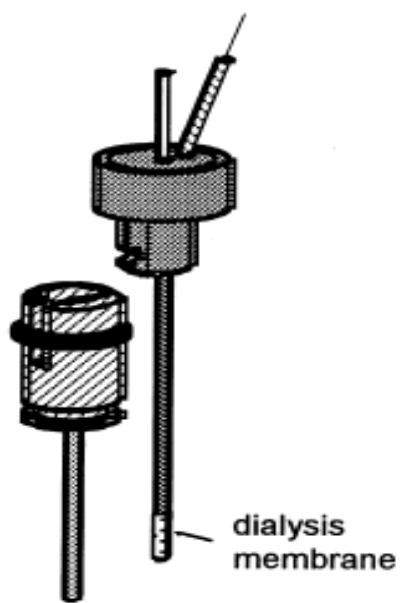

intracerbral

guide cannula

Figure 4a: Concentric cannula probe.

can automatically regularly to collect the dialysate. When the trace slowly pours the intercellular fluid infusion of the physiological buffer from the input hole to the tissues, the dialyzable substances from the extracellular fluid can penetrate through the dialysis membrane by passive diffusion process to the output hole, then the micro-sampler can be used to take the dialysate. The substances flow direction depends on the both sides of the membrane concentration gradient: the high concentration flows to the low concentration. The exogenous substances can penetrate through to the perfusion fluid. In most cases of some substances injected in the microdialysis system, the intercellular fluid components can penetrate through the semipermeable membrane with dialysis fluid output. The analysis of the dialysate composition can achieve the metabolism and tissue in vivo simultaneous monitoring of variations substances concentrations. The compounds concentrations in the dialysates samples reflect the substances concentrations in the tissues. Due to the slow filling and the diffusion resistance of the semipermeable in the tissues, all these factors will affect the incomplete recovery [14]. The tissue concentrations of compounds, which is known as $\mathrm{C}_{\text {tissue }}$ divided by the dialysate, which is known as $\mathrm{C}_{\text {dialysis }}$, is called as the relative recovery. The in vivo equation as follows:

Recovery $(\%)=100-\left(100^{*}\right.$ analytes $\quad$ concentration ${ }_{\text {dialysate }}{ }^{*}$ analytes concentration perfusate -1$)$. For the example, Stahle proposed the "retrodialysis" method applied in the human pharmacokinetic studies.
This principle stated that the diffusion process is quantitatively equal in both sides of the directions via the semipermeable membrane [15].

The Figure 3 illustrated the microdialysis probe schematic diagram. The probe is continuously perfused with perfusate that closely resembles the ionic composition of the surrounding tissue fluid at a low flow rate of approximately $0.1-5 \mu \mathrm{L} / \mathrm{min}$ [16]. Once inserted into the tissue or body fluid of interest, the small solutes can cross the semipermeable membrane by passive diffusion. The direction of the analyte flow is determined by the respective concentration gradient and allows the usage of the microdialysis probes as sampling as well as delivery tools [16]. The dialysate is collected at the certain time intervals for analysis.

The number of molecules per unit time across the membrane flux can be represented as $\mathrm{J}$ and the equation is shown as follows:

$$
\mathrm{J}=-\mathrm{PmA} \Delta \mathrm{C}=\frac{-\mathrm{DmA} \Delta \mathrm{C}}{\mathrm{t}}=\frac{-\mathrm{KTA}}{6 \pi \mathrm{k} \mu \mathrm{r}}
$$

In which Pm represents permeability, A represents the membrane area, $\Delta \mathrm{C}$ represents the inner and outer membrane of the concentration gradient, $\mathrm{t}$ represents the thickness of the sample, $\mathrm{k}$ represents the curvature, Dm represents the diffusion coefficient, $\mathrm{K}$ represents the Boltzmanne factor, $T$ represents the absolute temperature, $\mu$ represents the sample viscosity and $r$ represents the molecules radius. Following the above equation, suggesting that at the certain concentration gradients, the microdialysis membrane, J value not only dependent on the membrane parameters, but also dependent on the sample matrix characteristics.

\section{The Microdialysis Method Components}

The microdialysis system generally consists of the trace injection pump, connecting pipe, perfusion liquid, the probe microdialysis and the collector. Next, there is a specific animation below demonstrated to introduce the microdialysis process (Chart 1 ).

Chart 1 indicated that the main components of the microdiaysis system. Number 1 represents the trace injection pump, number 2 represents the perfusion liquid, number 3 represents the probe microdialysis, number 4 represents the connecting pipe and number 5 represents the microdialysates.

Firstly, we can implant in biological tissue with a semipermeable

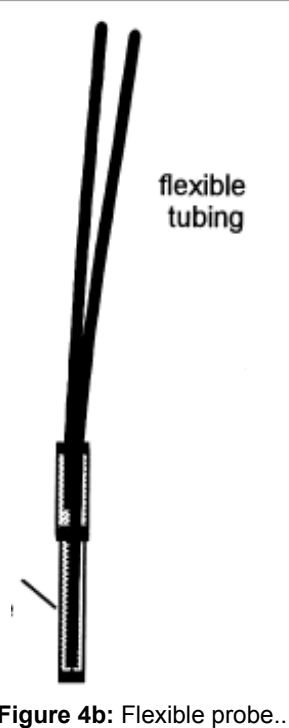




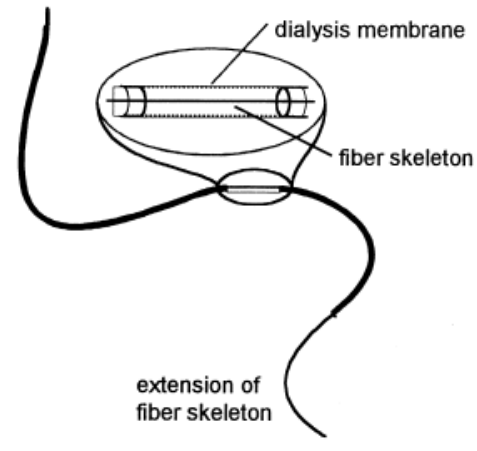

Figure 4c: Linear probe.

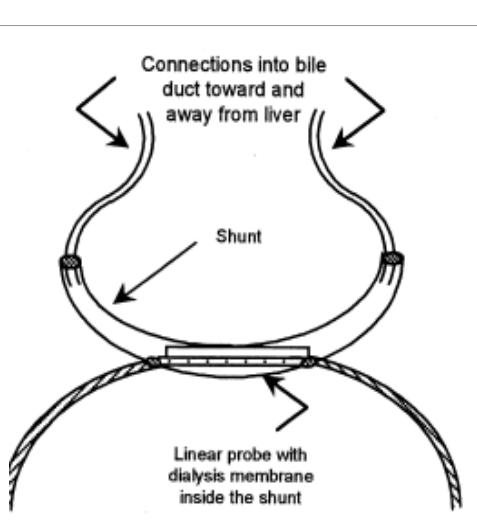

Figure 4d: Shunt probe.

membrane probe devices, this probe is quite similar to the artificial blood vessels. The dialysis membrane on the probe only can penetrate through the water and small molecules, the macromolecules due to the hindered by the barrier film cannot pass through. The probe connected to the two connecting pipes such as a liquid inlet pipe and the discharge pipe. The one end of the inlet tube connected to the very fine microperfusion pump at a constant speed push the perfusate through the probe. The tissue extracellular fluid of small molecules free drugs will follow the concentration gradient to cross into the probe by diffusion process. The combined protein molecules with the drug and other macromolecular compound cannot cross the microdialysis membrane because hindered by the membrane barrier. The diffusion of the drug will reach to the dynamic equilibrium state. The perfusate will be continuously flow out from the tube. The other end of the liquid pipe connecting to the collection equipment. After all these were set, the dialysate will be collected at a certain period of the time so as to achieve the purpose of sampled from the living tissue.

\section{The Probe is the Core Center}

Generally the microdialysis system consists of the trace injection pump, perfusion liquid, the probe microdialysis, the connecting pipes and the microdialysates. Among all of these, the microdialysis probe is the "core center"-the main components in this microdialysis system. Basically, it is usually composed of a tubular dialysis membrane that is installed in the double-layer casing made of quartz capillary steel or plastic. The dialysis membrane is a certain molecular weight substances can be retained the membrane, generally made of polyacrylonitrile, amino, cellulose and the others. All these materials have the better biocompatibility and stability, do not react with the body composition; their molecular mass retained materials in the range of 5000-10000 Dalton. The dialysis membrane production technology is marked with a laser in the membrane at a number of tiny holes. These MWCO (molecular weight cut off) holes are round and when this hole the MWCO reached to $5000 \mathrm{Da}$, it does not mean that the material molecular weight can pass through the holes. For the example, when the MWCO reached to $4999 \mathrm{Da}$, only the spherical shape can penetrate through the membrane, but this phenomenon states that this is impossible because the material is a certain spatial structure. Even though this case states that the molecular weight cut-off must reach to 5000-10000 Da, in fact only the molecular weight less than 1000 small molecules can pass through the holes as generally we studied the drug constituents are less than 1000 small molecules that can completely penetrate through the dialysis membrane.

\section{The Probe Considerations: Success of the Separation- Based Sensor Approach}

As generally we all know that the probe microdialysis is the core center in the microdialysis system, we have to choose the right dialysis probe and sampling situation during the microdialysis sampling process. It is due to the probe designs must have the suitable analyte recovery and required the spatial resolution for some tissues that are being interrogated. For the example, when we carried out the microdialysis sampling to the skin, the linear probe is selected as the suitable probe because the skin is in homogenous state and thus this probe can help to maximize the recovery and minimize the tissue damages. Next, we would like to describe the each type of the probe designs and their applications. The each type of the probe designs can be shown in the Figure 4 as follows.

Figure 4 demonstrated the each type of the probes designs. Figure $4 \mathrm{~A}$ represents the concentric cannula probe [17], figure $4 \mathrm{~B}$ represents the flexible probe [17], Figure $4 \mathrm{C}$ represents the linear probe [17] and Figure 4D represents the shunt probe [17].

\section{The concentric cannula probe}

This probe primarily is a concentric sleeve with the top of the sleeve dialysis membrane. The perfusate is flowing inside the pipe through the dialysis membrane to reach the sampling point. Zetterstrom et al. [18] was first time describing this probe in the 1983 [18]. This probe is mainly applied in monitoring the neurotransmitters release from the rat brains [19]. Besides that, this probe is also can be used in the drugs ocular sampling in anesthetized rabbits [20]. Due to the rigidity tube material of this probe, thus it is difficult to place this probe in the internal tissues, and mostly it is suitable used in the brain sampling probe.

\section{The flexible probe}

This probe design is firstly described by Telting-Diaz et al. [17]. This probe is mainly applied in the blood vessels sampling in the conscious animals. Even though this probe has its own limitations due to its rigidity, but this probe can help to compensate for the rigidity of the probe questions. There is an evidence study mounting that this probe was used in investigating the rat theophylline pharmacokinetic study [17].

\section{The linear probe}

Ungerstedt and Pycock were first proposing the linear microdialysis probes in early 1974 [21]. In the recent years, this linear probe is mainly used for muscle, skin, liver and tumor tissues of the drug loaded samples. For the examples, Zuo et al. [22] applied the linear probe for 
the in vivo microdialysis sampling in soft tissues.

Besides that, this probe is potential in monitoring the transdermal drug delivery. For the instances, Ault et al. $[23,24]$ applied the linear probe for the microdialysis sampling to investigate the dermal drugs transport. Zuo et al. [25] also used this probe to monitor the nicotine transdermal delivery by using the in vivo microdialysis sampling. From the study of the linear probe applied in the percutaneous administration, we found that this probe measured the sample was simple, direct and accurate rather than the blood sampling.

Apart from that, this probe can also be applied in studying the drugs distribution and metabolism in tumors. Palsmeier and Lunte conducted the microdialysis sampling coupled with the electrochemical detection system (LCEC) for investigating a benzotriazine compound, SR-4233 deposition and metabolism with the particularly cytotoxic effect for the oxygen deprivation tissue [26].

The linear probes have also can be used in vitro studies like the microsomal metabolism, drugs dissolutions and others. For the examples, Shah et al. $[27,28]$ applied this probe in the automated analytical systems for investigating the drug dissolution testing system based on the microdialysis sampling. Other examples are Gunaratna et al. $[29,30]$ applied this microdialysis probe to study the in vivo metabolism of the drugs in the liver microsomes. Zhou et al. [31] used this probe to carry out the automated analytical systems for the drug development studies by using the V.A. system to investigate the enzyme kinetic studies. Knaub et al. [32] conducted this probe in the automated analytical systems for the drug development study on the partioning of the lomefloxacin across an erythrocyte membrane in vitro. Apart from that, we found out the in vitro microdialysis sampling could reduce the sample preparation as applied in monitoring the corresponding bioprocess. For the example, Torto et al. [33] utilized the in situ microdialysis sampling for monitoring the bioprocess without the perturbation. Here by, throughout all these studies, we could find the microdialysis modes possess their advantages in preventing the analyte exhaustion.

\section{The shunt probe}

Scott and Lunte [34] were first time proposed this shunt probe in early 1993. This probe generally is made of a linear dialysis probe inserted with plastic tubing. This probe type can be mainly used for the continuous sampling especially for the bile sampling. By using the shunt probe applied in the bile sampling can provide us the information details about the drugs pharmacokinetics and hepatobilliary metabolism study. For the example, Scott et al. [34] conducted the shunt probe to carry out the in vivo microdialysis sampling to study the phenol and its metabolites in the bile, blood and liver of the rats. Gunaratna et al. [35] used the shunt probe to study the acetaminophen and its metabolites in vivo drug metabolism study. Hadwiger et al. [36] applied this probe type to study the tacrine and its metabolites pharmacokinetics in rat bile microdialysates. Heppert et al. [37] using the microdialysis shunt probe to monitor phenolphthalein glucuronide in rats with intact and diverted bile flow during the enterohepatic circulation, EHC.

\section{The Microdialysis Technology Quantitative Problems}

When the microdialysis technique applied in the drugs metabolism and pharmacokinetic studies, we all have to understand the microdialysis technique quantitative and qualitative process. The microdialysis sampling can be undergone under the non-equilibrium conditions; therefore the measured concentration of the compound dialysis probe, the sample is the compound in the matrix as part of the actual concentration. Due to the constant perfusion of the microdialysis probe with fresh perfusate, a total equilibrium cannot be established [38]. This results in dialysate concentrations that are lower than those measured at the distant sampling site. In order to correlate concentrations measured in the dialysate with those present at the distant sampling site, a calibration factor (recovery) is needed. The recovery can be determined at steady-state using the constant rate of analyte exchange across the microdialysis membrane. The rate at which an analyte is exchanged across the semipermeable membrane is generally expressed as the analyte's extraction efficiency (EE). The extraction efficiency is defined as the ratio between the loss/gain of analyte during its passage through the probe (Cin-Cout) and the difference in concentration between perfusate and distant sampling site (Cin-Csample). In theory, the extraction efficiency of a microdialysis probe can be determined by: 1) changing the drug concentrations while keeping the flow rate constant or 2) changing the flow rate while keeping the respective drug concentrations constant. At steady-state, the same extraction efficiency value is obtained, no matter if the analyte is enriched or depleted in the perfusate [38]. Microdialysis probes can consequently be calibrated by either measuring the loss of analyte using drug-containing perfusate or the gain of analyte using drug-containing sample solutions.

There are a few parameters that can affect the probe Extraction Efficiency (EE) such as the temperature, the perfusate liquid velocity, the chemical and physical properties of the dialysis membrane, the probe geometry, the membrane surface area, and the physical and chemical properties of the test compound and in the matrix diffusion rate. In the normal operating conditions for the microdialysis sampling, these parameters are generally are kept constant. Even though it does not establish a balance state, but it can quickly reach to the steady state. The recovery or release (delivery) experiments are used to determine the probe EE in the actual application process. In the recent years, the most frequently used calibration methods are the low-flow-rate method, the no-net-flux method [39], the dynamic (extended) no-net-flux method [39], and the retrodialysis method [40]. The proper selection of an appropriate calibration method is critically important for the success of a microdialysis experiment. Supportive in vitro experiments prior to the use in animals or humans are therefore recommended [38]. In addition, the recovery determined in vitro may differ from the recovery in humans. Its actual value therefore needs to be determined in every in vivo experiment [41].The brief procedures are shown as follows:

\section{External standard method}

Generally, we can simply use the recovery method in vitro aiming to calculate the changes in the relative concentrations of the test substances. After the microdialysis sampling process finished, the sample must be immediately measured, then the probe must be implanted into the known concentration standard solution, with the same flow rate in vivo perfusion probe. After the microdialysis sampling reached to the steady state, the perfusate could be collected for detection. The determination of the concentration of the standard solution concentration is the ratio of the in vitro recovery. Although this method is simple, but when the test substances in vitro and in vivo in different environmental conditions, therefore the test results cannot be strictly equal to the actual recovery.

\section{Internal standard method}

By applying this method, the known concentration of the analyte was added into the perfusate and another substance which had the similar properties of the analyte could be considered as the internal standard. The internal standard sample not only on the diffusion 
properties were consistent with the analyte, but we also keep it same in the in vivo metabolic process. The dialysis rate that measured can be classified as the analyte recovery rate [42]. Since the selection for the internal standard is very restrictive, thus limiting the internal standard method application.

\section{Retrodialysis}

The retrodialysis method is defined as when the microdialysis sampling process, the internal standard was added into the perfusate, then we could measure the compound into the tissues of the diffusion rate. Assumed that the test compound and the internal standard substance in vivo recovery of the amount of diffusion rate are same [43]. This method suggests that the internal standard (Cic) concentration that added into the perfustate must be kept in the same conditions with the in vivo dialysis so as this method could be performed to measure the perfusate internal standard concentration $(\mathrm{Cec})$ and the in vivo recovery rate (Rin,vivo).The recovery of this method can be recorded as the ratio of the drug lost during the passage(Cin-Cout) and the drugs entering into the microdialysis probe(Cin). In principle, retrodialysis can be performed using either the analyte itself (retrodialysis by drug) or a reference compound (retrodialysis by calibrator) that closely resembles both the physiochemical and the biological properties of the analyte. The following equation is shown as follows: $\mathrm{R}$ in vivo=(1 $\mathrm{Cec} / \mathrm{Cic}) \times 100 \%$. Even though the statement indicates that this method cannot applied in determining the endogenous compounds because it requires the analyte absence, thus this method is only preferred conducted for exogenous compounds for clinical studies [38]. This method has its advantages: convenient and time-saving.

\section{Extrapolation to zero flow rate}

In this method, generally when we are going to measure the microdialysate test compound concentrations under the different perfusion velocity conditions, with the obtained measured concentrations of the corresponding perfusion velocity, we could perform the non-linear regression. By applying the extrapolation to zero velocity to attain around the probe concentrations of the test compounds in the sample matrix estimation value of the time, assuming the concentration of the test compound in the sample matrix and the concentration of the probe membrane are in the equilibrium state, then the measured in the microdialysis sampling is the concentration of the test compound concentration in parts of the sample matrix. Note that throughout the course of the test compound that measured in the matrix should reach to the steady-state concentration.

\section{Use of a very low flow rate}

The low-flow-rate method is based on the extraction efficiency that is dependent on the flow-rate. At high flow-rates, the amount of drug diffusing from the sampling site into the dialysate per unit time is smaller (low extraction efficiency) than at lower low-rates (high extraction efficiency). At a flow-rate of zero, a total equilibrium between these two sites is established (Cout $=$ Csample). This concept can be facilitated for the (low-) flow-rate method, where the probe is perfused with blank perfusate at different flow-rates. Justice et al. [39] found that when the perfusate velocity which was less than $50 \mathrm{nlmin}^{-1}$, the compound of molecular weight less than $500 \mathrm{Da}$, the recovery was higher than $95 \%$. Under slow perfusion velocity conditions, when the recovery reached up to $100 \%$, the introduced errors were negligible. When applying this method in studies, in order to overcome the microdialysis sample collection and the analysis difficulties, the off-line analysis generally requires at least $2 \mu \mathrm{l}$ samples, so as the sampling time should be extend to collect the sufficient amount of the sample and thus the capability to handle a small sample of the existence of as series of problems like the sample evaporation problem. The concentration at the sampling site can be determined by plotting the extraction ratios against the corresponding flow-rates and extrapolating to zero-flow. The low-flow-rate method is limited by the fact that calibration times may be rather consuming before a sufficient sample volume has been collected. When conducting the online systems like microdialysis sampling combined with the capillary electrophoresis and capillary LC, thus makes it possible to analyse the nl amount samples.

\section{Method of no net flux}

During calibration with the no-net-flux-method, the microdialysis probe is perfused with at least four different concentrations of the analyte of interest (Cin) and steady-state concentrations of the analyte leaving the probe are measured in the dialysate (Cout) [38]. We can determine by plotting Cout-Cin over Cin and computing the slope of the regression line to obtain the recovery results. If analyte concentrations in the perfusate are equal to concentrations at the sampling site, no-net flux process will happen. The respective concentrations at the no-netflux point are represented by the $\mathrm{x}$-intercept of the regression line. At the steady-state, no assumptions about the behaviour of the compound in the vicinity of the probe have to be created, since the equilibrium existed at a specific time and place [41]. However, under transient conditions for the example after drug administration, the probe recovery may be altered resulting in biased estimation of the concentrations at the sampling site. To overcome this limitation, there are several approaches have been developed under non-steady-state conditions. One of these approaches is the dynamic no-net-flux method [39]. This method is more accurate than the retrodialysis method is that it is a compound with the actual study itself correction, but the operation is time-consuming process. The accuracy of the method depends on the accuracy of the measured concentration and the specific different number of the perfusate concentrations.

\section{The Dynamic no-net flux method}

When a single subject is perfused with various multiple concentrations during the no-net-flux method, multiple subjects are perfused with a single concentration during the dynamic no-net-flux (DNNF) method [39]. Data from the different subjects/animals is then combined at each time point for regression analysis permitting determination of the recovery over time. The design of the DNNF calibration method has proven very meaningful for studies that help to evaluate the response of endogenous compounds, such as neurotransmitters [39].

\section{Delivery method}

This method which is an improved method of the retrodialysis method can be applied in analogs overcoming the introduction of the internal standard uncertainties. This method is measured before the experiment the test compound to the target tissue in vivo release; the release rate is equal to the recovery rate. If possible, we can determine the release rate again after the experiment to confirm the probe behavior does not change during the experiment. If prerequisite of this method is the test compound concentration gradient regardless of the direction, it is assumed that in the study probes the tissue extraction efficiency must be kept in the constant rate.

\section{The Microdialysis Method Advantages}

To date, the microdialysis method is the sampling technology that can be conducted in monitoring the drug or metabolite concentrations 
in the extracellular fluid of the virtually any tissue. The microdialysis method possesses its advantages as follows: Firstly, is the time-resolved resistance, which means that various compounds in vivo can be continuously tracked the change with the time. For the instance, the analyte concentrations can be monitored over several hours, days or even for the weeks. The free, unbound extracellular tissue concentrations can resemble pharmacologically active concentrations at or close to the site of action. The combination of the microdialysis method with the modernized imaging technology like the positron emission tomography could help for measuring the intracellular concentrations. Secondly, is the spatial resolution verified that during the sampling process without the homogenate, can clearly revealed the true representative of the sampling sites in the concentration of the target compound. Meanwhile, the probe can be inserted into the selected target tissue location allows for evaluating the extracellular concentration gradients due to other factors influence like the perfusion differences. Hence, it has become a tremendous technique applied for the distribution researches. Next, the microdialysis method also revealed its important significance in pharmaceutical researches by providing the free proteins and other macromolecules free State small molecule compounds. The analyte exchange across the semipermeable membrane and the constant sampling fluid substitution with the fresh perfusate can prevent the sampling without fluid loss. By the microdialysis method application, it can be conducted without disturbing the tissue conditions and as combined with the other ways like applying the microinjection or pushpull injection. The semipermeable is very important for preventing the cellular debris, cells and proteins from entering into the dialysate. Due to the samples are free protein and enzymes macromolecules, a sample needed not to be clean up and the enzymatic degradation can be ignored, and the samples can be directly used by the pre-determination.

The MD technology has focused on more attention on the drug metabolism and pharmacokinetic studies. We can use this MD method to study the drug distribution, needless animals were sacrificed and the preparation of tissue homogenates, each experiment subject or animals can provide the complete concentration-time data, thus can improve the statistical accuracy and reduce the number of experiments animals. When carrying out the drug metabolism, it does not destroy the integrity of the body, we can maintain the actual physiological conditions, eliminating the traditional drug metabolism studies due to the tissue homogenization destroying the cell compartment resulting impact on the metabolic findings, at the same time we can attain the information about the drug metabolism in intermediate process information. The traditional method of measuring the serum, urine or feces metabolic concentration we can just understand the metabolic end product and does not reflect the middle process. When studying the pharmacokinetic study, it does not need the blood sampling, we can collect a large number of the samples from the same animals without loss of the body fluid volume. In order to avoid the traditional methods due to the hypovolemia caused by the blood after the drug distribution and elimination impacts, we can use the time-resolved resistance to get more accurate data in pharmacokinetic studies.

Other the microdialysis methods advantages are the MD membrane can provide the barrier not only protect tissues from the perfusate turbulent flow, but also the high molecular weight substances like bacteria [19], highly reproducible, minimally invasive, high -resolution real time sampling, highly dynamic continuous sampling and so on.

There are some examples have proven the microdialysis technology advantages. The percutaneous microdialysis technique can continuously monitor the skin tissue interstitial fluid endogenous and exogenous substances, causing the minimal damage to the tissue and does not influence the tissue surroundings. There is a mounting evidence has shown that [44] after the $12 \mathrm{~h}$ of microdialysis experiments, the probe implanted into the surrounding tissue for detection and found that there was no bleeding obvious inflammation. The microdialysis probe implanted in the specific organs or tissues to direct observation site called in-situ sampling, which is characterized by a more realistic and effective local tissue reflect the real situation observed in substance. In addition to that, the microdialysis method in the skin pharmacology studies revealed the unique advantages such as monitoring the percutaneous absorption of the drug in the metabolism process, the drug distribution in the skin, the skin effect of the drug on the enzyme, the detection of the inflammatory cytokines in the skin and even be used as an alternate route of the administration [45].

\section{The Microdialysis Method Limitations}

Compared with the other technology, even though there are several researchers tried to make the microdialysis probes smaller and effective, but this MD technology still has its own limitations. For the example, when the probe implanted in the tissue, it will affect the surrounding tissues changes such as the biochemical indicators changes, these changes will be misunderstood as the drugs or diseases factors influence and thus will disturb the experiment outcomes. Even though there are increasingly articles demonstrated that the probe implantation will not affect the surroundings, but the microdialysis probe can alter tissue morphology resulting in disturbed microcirculation, rate of metabolism or integrity of physiological barriers, such as the bloodbrain barrier [46]. But however, with respect to the surrounding tissue and implanted probes, the impact of the organisms there are still some controversies. As implanted the probes of different sizes and materials, the impact on the surrounding tissues are not the same, but as a foreign body implanted biological probes body, it will first elicit an immune response [47]. Therefore, we have to take the consideration for the long-term sampling as they might affect the study outcomes. The micordialysis experiments must be performed within an optimal time window, usually 24 to 48 hours after the probe implantation $[48,49]$.

After a certain time the probe implantation, the fibrosis occurs around the local tissue, which also affects the recovery of the probe [50-52], especially in vivo experiments. In the recent studies, there are extensive range of calculating the target substance in the extracellular fluid and the dialysate concentrations mathematical models, but each of the method has some deficencies, therefore there is a need for building a better mathematical model to meet the actual needs. When the microdialysis probe direct coupling of analytical instruments, the probe volume of the tubing between the detector may cause the excessive dead volume and the lag response time, hence affecting the reliability of the results, which is in the minor and trace analysis of the time impact larger. But however, in the study practice, the flow rate cannot be reduced too much since either the sample volume attained for analysis will be inadequate or the temporal resolution of the experiment will be lost. As consequently, it is essential to optimize the relationship between flow rate and the analytical assay sensitivity. This condition may be more complex for lipophilic compounds as they can stick to the tubing or other probe components, resulting in a low or no analyte recovery.

Besides that, the microdialysis technology also has other limitations such as training of the required skills, the probe manufacturing, drugspecific problems displayed, sensitive analysis needed and the others. 


\section{The Microdialysis Technology Applications in Drug Metabolism and Pharmacokinetic Studies}

\section{Study the drug to the central nervous system (CNS) distribution and transshipment}

The microdialysis technology was first applied in the drugs pharmacokinetic studies of the brain researches mainly to examine the drugs distribution and transport in the brain. It was partly due to the microdialysis technique that was originally developed for the neurochemical research, while it also due to the early micordialysis probe rigid design which just suitable for placing the brain. The cerebral microdialysis determination has obvious advantages rather than other methods used to measure the brain tissue distribution and transport, such as a row of the single sampling to measure the animals CNS free drug concentration possess the excellent time and spatial resolution, but also in the drug selectivity determination without the metabolites interferences. Using the brain microdialysis sampling technique of the drug distribution and transshipment of the various quantitative aspects of the problems have been fully described in the literature [53]. There are a significant number of the documents reporting the CNS related to the drug distribution and transshipment. The brain microdialysis technique is particularly suitable for the study of the brain tumor cancer drugs to the tumor site distribution and the pharmacokinetics. The brain microdialysis technique is also appropriate to study the drug in the blood-brain barrier penetrating, antibiotics and pain medications such as central a useful tool in the CNS distribution. For the example, Desrayaud et al. [54] conducted the blood and brain microdialysis method to investigate the P-glycoprotein inhibitor SDZPSC833 effects towards the colchine distribution across the blood-brain barrier. Xie et al. [55] applied the blood and brain microdialysis method to investigate the highly-lipophilic substances codeine distribution across the bloodbrain barrier in rats brains.

Besides that, Graff et al. [56] and Illum et al. [57,58] conducted the intranasal drugs administration on the brain targeting for limiting the BBB permeability and inactivating the biological effects substances on the CNS. Feng et al. [59] also used the intranasal and intravenous administration to investigate the rats brain pharmacokinetics of the tetramethylpyrazine. As a result, they found that the intranasal and the absorption amount was similar to the intravenous administration.

In addition to the microdialysis technology not only can be applied in the drugs distribution and the pharmacokinetics studies, this technique is still can be used in biochemistry application in the traumatic brain injury research. Generally, this microdialysis technique applied in the cerebral ischemia, hypoxia and the brain damage mechanism. We basically will measure the following indicators like the excitatory amino acid, lactic acid, pyruvic acid, glucose, glycerol, lactate/glucose ratio and lactate/pyruvate ratio and other energy metabolism indicators; the monoamine neurotransmitter, acetylcholine, NO, purine, neurotransmitters and prostaglandins 5 -seronin and other ingredients for determination, then observing the ischemia, hypoxia and the brain damage during the extracellular concentrations of the biochemical substances dynamic changes. All these indicators changes and their clinical significance can provide usthe important information about the traumatic brain injury patients after injury, treatment and posttreatment. The microdialysis probe at the puncture site to selectively insert the receptor inhibitors, agonists, as well as the neurotransmitter metabolism enzyme inhibitors, activators, so as we can study the nerve receptors, ion channels, neurotransmitters regulation law, at the same time we also can explore the cerebral ischemia, hypoxia, brain trauma, brain tumors, epilepsy, subarachnoid hemorrhage, the drug dependence and the mental disorders in the mechanism [59-62].

Berger et al. [63] applied the microdialysis technique to carry out the acute cerebral infarction, subarachnoid hemorrhage and severe brain injury of 50 patients in the clinical studies, with the CT scanning they could observe the three sections of the brain tissues that affecting the CNS chemical properties changes: (1) No infection and damage to the normal brain tissue microdialysis evaluation; (2)Infarct center with the adjacent areas of the brain tissue neurochemical changes are reversible; (3) The large area of infarction regional centers irregular changes in the concentrations of the chemical substances. The study revealed that the chemical changes in the brain were closely-orientated with the clinical course, treatment and prognosis. The excitatory amino acids (EAA), including the glutamic acid and aspartic acid in the brain cell damage induced by the ischemia has been widely recognized. For the animal experiments, the cerebral ischemia excessive EAA release lasted only within 1 2hours, and the human brain ischemia EAA release will not only achieve the high level, but also can maintain the duration up to 7 to 8 days. Kimelberg used the microdialysis technique to carry out their study and found that the quantitative regulation anion channel sensor damage during the cerebral ischemia, the stellate cells the glutamate transporter reversal. In the early stage release of about EAA by anion channel $80 \%$ of total emissions, thus leading to excessive release of EAA. The application of the valid anion channel blocker tamoxifen that performed the inhibition of the EAA release and effectively protecting the neurons. The mice treatment with the tamoxifen in the middle cerebral artery occlusion model indicated that about $80 \%$ was very effective in the ischemic $3 \mathrm{~h}$ window period after the occurrence of the beginning of the treatment and found also the infarct size decreased [64]. Lin et al. [65] conducted the dual probe implanted in the cerebral cortex to monitor the gerbil magnesium sulphate and glutamic acid effects on the energy metabolism after the cerebral ischemia and reperfusion. The studies had shown that the gerbil model of the cerebral ischemia microdialysate glucose level reduced by $10 \%$, $15 \%$ reduction of pyruvate level, lactate level increased to $200 \%$ and the glutamic acid lipid increased to $1400 \%$. When given the magnesium sulfate treatment, the ischemic side the glucose level increased $50 \%$, the pyruvic acid enhanced $70 \%$, the glutamic acid and the lactic acid levels decreased $500 \%$ and $150 \%$ respectively. The results indicated that the magnesium sulfate treatment of the cerebral ischemia and reperfusion during and after recovery, this treatment could maintain the cellular energy metabolism and effectively reducing the release of the glutamate fat, thus implying that this treatment could perform a significant neuroprotective effect. Maurer et al. [66] conducted the microdialysis technique to carry out the analysis of protein expression patterns of the brain. The samples were collected from the patients with impaired cerebral hemisphere contralateral limb. There were two types of techniques could be performed during the proteins separation such as the protein gel electrophoresis and mass spectrometry techniques. In this study, they found that about $158(\mathrm{~N}=18)$ protein spots were able to identify 95 sites, a total of 27 monomeric protein expression, most of the protein in the previous experiments can be measured from the human brain, but there are 10 proteins mainly from the brain intracellular proteins can determine the unique microdialysis, which is not present in the cerebrospinal fluid. The studies have indicated that the human brain microdialysis protein components with the patient's clinical symptoms and outcomes in patients with brain imaging may help the nerve injury diagnosis, treatment and prognosis judgement.

Apart from that, the microdialysis technique can be applied in the hypothermia therapy of the traumatic brain injury. Berger et al. 
[67] studied the 12 cases of the middle cerebral artery infarction mild hypothermia $\left(33^{\circ} \mathrm{C}\right)$ treatment, the CMA600 automatic analyzer microdialysis was used to determine the glutamic acid, glycrol, pyruvate and lactatae levels. In the brain CT scan, the microdialysis probe will be placed in the three different regions of the brain: (1) the brain tissue without damaged and has a stable dialysate concentrations of the glutamate $2.6 \sim 3.6 \mathrm{mmol} / \mathrm{L}$, lactate $1.8 \sim 3.0 \mathrm{mmol} / \mathrm{L}$, pyruvate $50.0 \sim 95.8 \mathrm{mmol} / \mathrm{L}$, all these revealed that the hypothermia treatment was effective; (2) Measurement of the tissue infarction edges of the therapeutic hypothermia, the glutamic acid $4.8 \sim 12.6 \mathrm{mmol} / \mathrm{L}$, the glycerol $58 \sim 82 \mathrm{mmol} / \mathrm{L}$, lactate $0.7 \sim 1.3 \mathrm{mmol} / \mathrm{L}$, pyruvate $13.3 \sim 36.8$ mmol/L.; (3) the permeate from the irreversible damaged tissue, the excessive glutamate $(453 \mathrm{mmol} / \mathrm{L})$, glycerol $(1187 \mathrm{mmol} / \mathrm{L})$, lactic acid $(12 \mathrm{mmol} / \mathrm{L})$, pyruvate $(4 \mathrm{mmol} / \mathrm{L})$, all these indicated that there were no effectiveness in the infarct area in the hypothermia therapy. Chou et al. [68] applied the microdialysis technique to monitor the mouse model of the heatstroke extracellular dopamine in the brain, after using the hypothermia therapy, the dopamine and glial fibrillary acidic protein quantities and levels reduced, the mean arterial pressure began to fall from a higher levels. From these studies shown that hypothermia could reduce the excessive secretion of dopamine and nerve fibers damage [68].

\section{Study drug in peripheral tissues and organs pharmacokinetics}

The microdialysis technique applied in the skin and subcutaneous adipose tissues pharmacokinetics studies

\section{The bioavailability, BA and bioequivalence, BE evaluation}

The FDA issued in 1998 to evaluate the bioequivalence of the topical formulations draft guidelines, which provides the skin with the drug pharmacokinetics (dermato pharmacokinetic, DPK) parameters to evaluate the bioequivalence topical formulations, including drugs in every unit area of the skin AUCt, $\mathrm{C}_{\max }, \mathrm{T}_{\max }$ and other indicators, but the draft was withdrawn by 2002 . BA and $\mathrm{BE}$ reflects the release of the pharmaceutical active ingredients into the bloodstream, thereby reaching to the effective parts of the onset rate. $\mathrm{BA}$ and $\mathrm{BE}$ are the pharmacokinetics parameters to evaluate the preparation quality or the important indicator of the viability of new dosage forms. Generally, Cmax was the most frequently used drug bioequivalence indicators to evaluate the bioequivalence of the systemic administration of the main indicators. For the target which is not the topical skin agents, as using the corresponding index as a skin after the topical bioequivalence the evaluation still appears some questions. The drug through the skin tissue metabolism and the pharmacological effects are difficult to use the other traditional methods of sampling to carry out the study. The ideal partial onset the transdermal preparations requires the ability to absorb rapidly the administration and disposition sites, but the amount of the drug in the blood circulation is required not too high. Currently, the administration can be used for the skin preparation bioequivalence study method is very limited, but the DMD technology minimally invasive, real-time characteristics make it as an ideal tool for BA/BE studies. Tettey-Amalalo et al. [69] carried out the study.18 subjects were given ketoprofen gel and underwent the DMD sampling. The DMD technology analysis was applied to evaluate the BE feasibility and they found that through the DMD sampling was difficult to obtain the accurate sampling DMD peak concentration(Cmax) data, therefore could conducted the drug-area under the curve (AUC) as a evaluation index. In this study, the UPLC applied for the ketoprofen separation time only $1.1 \mathrm{~min}$, very fast and efficient. Mathy et al. [70] conducted the subcutaneous and blood double-digit points microdialysis sampling method to investigate and compare the intravenous injections and skin gel two kinds of the fluconazole formulations in rats skin and plasma pharmacokinetic parameters. The results revealed that by 10 mg. $\mathrm{kg}^{-1}$ after the intravenous administration, the fluconazole quickly penetrating into the skin, blood and dermis and found that the free drug concentration-time curve was similar, the AUC value was (5985.1 $\pm 192.3) \mu \mathrm{g} \cdot \mathrm{min} \cdot \mathrm{ml}^{-1},(5943.9 \pm 200) \mu \mathrm{g} \cdot \mathrm{min} \cdot \mathrm{ml}^{-1}$ respectively. After the skin topically administrated fluconazole gel $0.5 \mathrm{~g}$, the AUC value was $(271.7 \pm 28.4) \mu \mathrm{g} \cdot \mathrm{min} \cdot \mathrm{ml}^{-1}$, Cmax value reached to $(637.1 \pm 177.8)$ ng.ml-1, MIC value was $\left(0.25 \sim 0.5 \mu \mathrm{g} \cdot \mathrm{ml}^{-1}\right)$. Brunner et al. [71] carried out the new spray gel diclofenac study on comparing the transdermal blood concentration after the administration, subcutaneous tissue and skeletal muscle distribution of hydrochlorothiazide sodium oral preparation, DMD was used to determine the subcutaneous fat drug concentration, as a result implying that the gelling agent relative bioavailability of subcutaneous and oral administration of the skeletal muscle were $344 \%$ and $209 \%$ respectively, the blood drug concentration only $50 \%$ of the oral administration, hereby recognized that the new formulation had a good local permeability and lower distribution systems, therefore this new formulation could be used as an alternative to oral dosage formulation for soft tissue inflammation therapy.

The DMD poor reproducibility is not yet overcome, thus will affect the BE major factor in the accuracy of the evaluation results [72]. The samples may cause the DMD differences such as the skin permeability of the tested individual differences and the probes embedded operating stability. The buried depth probe will affect different sample concentrations, but through repeated practice and with the ultrasound scan testing can improve the buried depth stability [73]. Gracia et al. [74] in the study of the metronidazole BE, the 14 subjects were selected for the DMD sampling and found that the differences in DMD samples affecting the test results. Benfeldt et al. [75] recognized that the $\mathrm{BE}$ study the sample size should be at least 18 people or more and suggested that to be non-invasive means of measuring the skin temperature, skin moisture loss volume and subcutaneous blood circulation evaluated to analyse skin function and permeability individual differences.

\section{Monitoring the skin inflammatory mediators}

The conventional method for observing the local skin inflammation is often limited and just focusing on the observation the skin colour, temperature, transcutaneous water loss (TEWL) changes, but it is difficult for accurate continuously observing a variety of inflammatory skin inflammatory reaction media. Based on the microdialysis technique real-time and minimally invasive, the skin inflammation that associated with the inflammatory molecules can be accurately and efficiently monitored by the microdialysis method.

Fulzele et al. [45] facilitated the jet fuel JP-8 and xylene to stimulate the SD rats skin for $2 \mathrm{~h}$, induced the skin acute inflammation. The linear probe (length $10 \mathrm{~mm}$ ) implanted into the dermal layer, then the EIA was used to measure the microdialysis samples SP, CGRP and PGE2 changes. The stimulus used to induce significant SP, PGE2 release but no induction of CGRP. When observing the SP antagonists and PGE2 inhibitor pretreatment experimental group, the inflammation induced SP, PGE2 decreased. The study using the skin microdialysis technique dynamic monitoring JP-8 and other irritants cause the skin irritation after the inflammatory mediators release, then could carry out the accurate quantification.

Patlolla et al. [76] applied the nonane, dodecane and tetradecane in SD rat dorsal skin to hair stimulation. By combining the skin microdialysis method with the enzyme immunoassay could determine the local inflammatory skin reaction four kinds of inflammatory 
markers like SP, a-MSH, IL6 and PGE2 changes. The results showed that the nonane, dynamic dodecane after the stimulation of the rat skin, the dialysate SP, a-MSH and IL-6 increased significantly and the tetradecane inflammatory factors without causing a significant increase. Compared with dodecane and tetradecane, after the skin stimulation by nonane within $2 \mathrm{~h}$ can significantly increase PGE2 release; after the nonane and dodecane irritating the skin, IL-6 release more slowly, but after 5 h stimulation the IL- 6 release speeds up 2 to 3 times. The results indicated that three kinds of stimuli from the cellular level of irritation to the skin cells of the dermis order: nonane $\geq$ dodecane $\geq$ tetradecane. The studies have revealed that chemical stimulation of the skin, the skin using the microdialysis technique to monitor changes in inflammatory markers was an efficient and accurate method. The microdialysis probe implanted under the skin, after $2 \mathrm{~h}$ of balance to the skin tissue of normal physiological conditions almost no interference, which could be more accurate monitoring the molecular changes associated inflammation. The combination usage of the microdialysis techniques and the modern instruments can analyse the dialysate composition quickly and efficiently and thus becoming a great demand of the study needs.

\section{Monitoring the subcutaneous adipose tissue endocrine}

People in the past recognized that the subcutaneous adipose tissue was only the part of the fat storage, but recently more and more researches showed that the adipose tissue was an important endocrine organ [77], could secrete adipokines, chemokines, inflammatory cytokines and by going through the secretion of the biological media related organizations to regulate various metabolic, inflammatory and immune system. However, as regards the secretion of the biological media in adipose tissue distribution studies also rarely reported.

Dostlov et al. [78] applied the microdialysis techniques to monitor the 9 female patients with anorexia nervosa and 11 normal subjects abdominal subcutaneous adipose tissue secretion of leptin. The RIA was used to measure the anorexia nervosa patients and normal adipose tissue in vivo concentration of free leptin was no significant difference, with $(2.36 \pm 0.25)$ ng. $\mathrm{ml}^{-1}$ and $(2.59 \pm 1.99) \mathrm{ng} \cdot \mathrm{ml}^{-1}$ respectively. The ELISA was used to measure patients with anorexia nervosa in vivo plasma leptin soluble receptors (Ob-R) expression level was higher than in normal subjects groups, with $(58.05 \pm 38.69) \mathrm{Uml}^{-1}$ and $(12.79 \pm$ 5.08) $\mathrm{U} \mathrm{ml}^{-1}$ respectively, $\mathrm{P} \leq 0.01$. The studies had shown that patients with anorexia nervosa the plasma leptin concentration reduced was not because of its secretion in adipose tissue decreased, but was closelyrelated to the patients plasma sOb-R high expression.

Dostlov et al. [79] also used the microdialysis technique combined with flow fluorescence monitored 17 healthy women after oral administration of glucose, the abdominal subcutaneous adipose factor was in the changes within $24 \mathrm{~h}$. The results indicated that in the localized adipose tissue, IL-6, IL-8, MCP-1,HGF, adiponectin, resistin and leptin were found a large fluctuation range within $24 \mathrm{~h}$ observation period. The subjects after oral administration of glucose within $1 \sim 3 \mathrm{~h}$, the adiponectin and resistin concentrations in adipose tissue significantly increased, the leptin and PA-1 concentrations decreased, implying that the body glucose uptake could significantly affect the fat tissue endocrine function. The studies indicated that the application of the microdialysis combined with high-flow fluorescence technology monitoring the human subcutaneous adipose tissue of various cytokines, biologically active proteins, therefore could be in depth investigating the related metabolism mechanisms and providing the new ways to study the subcutaneous adipose tissue metabolism.

\section{Study on the transdermal formulations of topical skin}

In generally, the external preparation for the skin study was limited by the research methods and analysis equipment, but with the continuous development of the modern analytical technology provides the great convenience for the external preparation of the skin study. There are two types of the conventional ways of the skin external preparation for percutaneous absorption in vivo and in vitro. The in vitro study will use the material for the artificial semipermeable membrane and the human or animal skin in vitro, as the result the in vitro studies cannot reflect accurately the absorption of the drug in the skin, distribution, metabolism and other local outcome pharmacokinetic process; the in vivo study method is such that the skin need to be excised to prepare the homogenates and then reanalysis the media or drug content, which cannot fulfill the minimally invasive, dynamic, precise quantification and other basic research requirements, but also cannot solve the isotopically labeled drawbacks. In situ using the microdialysis sampling has little effect on the surrounding tissues and having the continuous observation characteristics. This method can be used to overcome the limitations imposed by the conventional methods, especially for the skin external preparation for percutaneous absorption studies with the relevant research to a great convenience.

Sun et al. [80] applied the microdialysis technique combined with the ultra-fast liquid chromatography (UFLC) monitoring antifungal itraconazole iodide in rat skin after topical dermal tissue concentrations and the effects of the homemade probe recoveries. The injection volume was $10 \mu \mathrm{l}$, the lowest limit of quantification (LLOQ) was 0.2 $\mu \mathrm{g} / \mathrm{ml}$, the itraconazole iodide retention time of only $1.37 \mathrm{~min}$, the internal standard retention time was $1.78 \mathrm{~min}$. The iodide itraconazole in vitro and in vivo calibration experiments probe recoveries were $48 \%$ and $34 \%$. The research results indicated that using the microdialysis coupled with UFLC determination intraconazole iodide concentration after the percutaneous absorption was a highly stable method.

Gao et al. [81] applied the LC-MS/MS method for detection of human plasma microdialysis samples itraconazole iodide concentration. To improve monitoring the efficiency and reduce the environment impact of the surrounding implanted probes, the microdialysis sampling generally requires relatively small amount about $5 \sim 10 \mu \mathrm{l}$, even sample volume of only $1 \sim 5 \mu$, therefore the trace sampling for the analysis equipments suggest the high demands.

Besides that, in the recent studies had shown that the amitriptyline had a local analgesic effect [82]. Patel et al. [73] administrated amitriptyline to the rabbit skin to the hair, $100 \mu \mathrm{A} / \mathrm{cm}^{2}, 200 \mu \mathrm{A} / \mathrm{cm}^{2}$ and $300 \mu \mathrm{A} / \mathrm{cm}^{2}$ respectively intensity of iontophoresis treatment $60 \mathrm{~min}$, the DMD combined with the high performance liquid chromatography (HPLC) method to determine the subcutaneous administration of the drug concentration and determination of plasma concentration. The three intensities of iontophoresis after the subcutaneous drug-area under the curve (AUC) respectively of $(19 \pm 7) \mathrm{mg} \cdot \mathrm{min} / \mathrm{L}^{-1},(119 \pm 56)$ mg.min $/ \mathrm{L}^{-1},(615 \pm 302) \mathrm{mg} \cdot \mathrm{min} / \mathrm{L}^{-1}$, while the plasma concentration was always below the detection limit, indicating that iontophoresis technology could promote the amitriptyline local skin penetration and into the blood was very low, thus reducing the drug into the circulatory system of the central nervous system effects. Shukla et al. [83] studied the acyclovir formulations of different semi-solid formulation excipients in rabbit skin absorption differences, with the iontophoresis were given neutral pH 11 alkaline oitments and gels, the results revealed that a gelling agent in $\mathrm{pH} 11$ dermal uptake was significantly higher than neutral semi-solid preparations. 
The DMD technology advantage is the ability to be sampled in the body and to maintain the structural integrity of the skin, thus if compared with the skin from the conventional pharmacokinetic sampling method, the accuracy was much greater. The DMD can be multilocus implanted, thus can compare the same kind of the preparation in normal skin penetration of the skin with the diseased skin absorption characteristics. Ortiz et al. [84] used the DMD and tape peeling sampling method respectively to determine the metronidazole irritant dermatitis of the skin permeability, as a result indicating that the prevalence DMD subcutaneous drug concentration was at 3 times the normal skin, while the obtained tape peeling contrast to the results of the sample measured. After that, in order to compare the two methods atopic dermatitis and normal skin creams on the absorption of metronidazole [85], the DMD sampling method showed the drug concentration in diseased skin was 2-4 times to the normal skin, and tape stripping concentration of the sample results showed no significant difference. These results indicated that the choice of sampling transdermal absorption of drugs directly affected the measurement results, and DMD method can be used for such studies.

\section{Investigation skin distribution system administration}

The DMD technology applied in the system administration of the pharmacokinetics have the following meanings: skin or soft tissue as the target organ of the drug, we can evaluate the skin drug concentration and study the skin on the side effects of the drug. Traunmuller et al. [86] compared and studied the patients with the diabetic foot infection complications by intravenous injection with linezolid $600 \mathrm{mg}$ and found the healthy skin, inflammation of the subcutaneous tissue and cancellous bone in the pharmacokinetic parameters, the Cmax was $(15.5 \pm 2.5) \mathrm{mg} / \mathrm{L},(15.8 \pm 2.8) \mathrm{mg} / \mathrm{L},(15.1$ $\pm 4.1) \mathrm{mg} / \mathrm{L}$ respectively, recognized that this concentration could effectively inhibit the peripheral soft tissue infections. Traunmuller et al. [87] made another study on the clarithromycin in the subcutaneous adipose tissue pharmacokinetic characteristics. Six healthy subjects were chosen for 2 times a day, each $500 \mathrm{mg}$ dose of oral administration of clarithromycin, after the plasma concentration reached to the steady state, then measured the subcutaneous tissue drug concentrations, the results indicated that the subcutaneous drug concentration AUC 0 24 $\mathrm{h}$ was $(0.84 \pm 0.19) \mathrm{mg} . \mathrm{h} / \mathrm{L}$, and the blood AUC ratio of $(0.39 \pm 0.04)$, proposed that this dose could not reach the treatment of the skin and soft tissue infections effective concentration.

The DMD sampling may reflect the drug concentration in the skin changes over the time, therefore in the recent years the studies had verified and established with the DMD concentration-time characteristics to reflect the in vivo blood plasma levels changes or vice versa predicted the concentrations based on the plasma concentrations of the subcutaneous. Englemen et al. [88] proposed and validated to the skin alcohol concentration-time variation to characterise the drinker alcohol contents by selecting the adult Wistar rats and alcoholics rats for the study. First of all, all the rats were injected intraperitoneally with dose $0.5 \mathrm{~g} / \mathrm{kg}, 1.0 \mathrm{~g} / \mathrm{kg}, 2.0 \mathrm{~g} / \mathrm{kg}$ of the ethanol, the results measured obtaining the subcutaneous DMD sample concentration reached a maximum at $15 \mathrm{~min}, 70 \mathrm{mg}, 123 \mathrm{mg}$ and $203 \mathrm{mg}$ respectively, then gavage and intraperitoneal injection, $1.0 \mathrm{~g} / \mathrm{kg}$ doses of ethanol were given to rats, compared the blood alcohol concentration- time curve and subcutaneous DMD sample concentration-time curve, thus suggesting that both of them were relevant. Shukla et al. [89] injected intravenously rabbits with amoxicillin and cefuroxime, using the DMD sampling to measure the subcutaneous drug concentration and simultaneous determination of the plasma concentrations, then calculating the blood- subcutaneous drug distribution constant Kin(plasma concentration/ subcutaneous concentration) and Kout (subcutaneous concentration/ plasma concentration). By establishing the distributed constant blood concentration prediction method subcutaneous drug concentration, compared the DMD actual results, implying that a concentration closed to the actual concentration of the drug according to the method predicted.

\section{The pharmacodynamics and mechanism study}

The DMD is mainly used to study the skin inflammation and skin blood circulation regulation mechanisms. In the recent years, there were many articles reported for the tumor necrosis factor(TNF- $\alpha$ ), IL-1,IL-6,IL-8, prostaglandin (PG), iso-prostaglandin F(2)-IsoPs, histamine and other inflammatory cytokines [90-94] to carry out the MD sampling, so as could evaluate the local anti-inflammatory drug pharmacodynamics. Shinkai et al. [95] using the croton oil to establish the rat skin inflammation model, after the MD probe was implanted in the subcutaneous, then given the felbinac patch, the MD sample drug concentration was measured, wherein the PGE-2 levels were measured, the results showed that croton oil significantly increased the subcutaneous PGE-2 levels, while providing $0.5 \%$ or $3.5 \%$ felbinac patch after $2 \sim 5 \mathrm{~h}$, the PGE-2 levels were significantly decreased. In Shinkai et al. [96] another study had proven that the transdermal ketoprofen significantly reduced the PGE-2 skin content and the joint fluid. Brazis et al. [97] studied the impact cyclosporin A on the Beagle dogs skin histamine and PGE-2 levels, the results showed that histamine levels were significantly decreased after treatment 15 30 days, but the PGE-2 levels did not change significantly, indicating that cyclosporine inhibiting the release of anti-inflammatory effects of histamine. Study the physiological mechanisms of skin diseases is also a major application areas DMD. With the laser Doppler blood flow measurement, while DMD as sampling and mode of the administration; we can access the local skin blood flow mechanism to verify. For the example, Hubing et al. [98] buried the MD probe to the human forearm, then perfusing the respectively PG inhibitor ketorolac, nitric oxide (NO) synthase inhibitor, L-arginine methyl-ester and saline solution to verify the skin flushing vasodilation regulation was closely-related to the PG and NO.

\section{Study the traditional Chinese medicine metabolic percutaneous}

The traditional Chinese medicine active ingredients are too much, the in vivo and in vitro metabolism mechanism is too complicated. The skin microdialyisis sampling method used to study the traditional Chinese medicine active ingredients through the skin metabolism the pharmacokinetic studies are very highly-efficient. In the recent years, the traditional Chinese medicine were used to study the skin new formulation absorption and distribution like measuring the Sinomenine skin drug content and pharmacokinetic parameters [99], determination of the peurarin subcutaneous content [100] and others.

Aconitum for the example of the traditional Chinese medicine can show the significant effect in the treatment rheumatic diseases, but this kind of the traditional Chinese medicine containing toxic alkaloids such as aconitine, currently in vitro using the aconitum to study the traditional Chinese medicine in vivo metabolism process is rare, it is due to its safety evaluation has not been established. Zhang et al. [101] used the microdialysis coupled with the LC-MS/MS technology to determine the aconitine drug concentrations in the rats plasma and in vitro transdermal skin dialysate. In this study and found that the investigation aconitine inter-day and intra-day stability were good, the in vivo recovery of the probe was $(34.48 \pm 3.05) \%$. At the different $\mathrm{p} \mathrm{H}$ environments, the aconitine was unstable and degraded rapidly in an 
alkaline environment, but good stability under the acidic conditions. The use of the plasma ultrasonic extraction method is simple, only $1 \%$ trichloroacetate (containing $10 \mathrm{ng} / \mathrm{ml}$ propafenone hydrochloride internal standard and acetonitrile solution) was used to precipitate the proteins and other impurities, then LC-MS/MS could be directly used to test the samples. The analysis of plasma with less sample preparation method is simple, can reduce the loss of aconitine and improve the detection rate. Studies have shown that the use of percutaneous pharmacokinetics after administration of aconitine microdialysis study has important reference value for the use of safety evaluation aconitine.

Sophora alkaloids and oxymatrine which are the strongest efficacy in the traditional Chinese medicine, sophora, widely used in the treatment of viral hepatitis, myocarditis, cancer, psoriaasis and other diseases. Zheng et al. [102] conducted the microdialysis combined with HPLC-MS/MS to study the oxymatrine gels in the rats skin and plasma microdialysate samples the topical metabolic parameters, the Oxymatrine in vivo blood vessels and skin probe recoveries were (31.1 $\pm 7.6) \%$, and $(26.7 \pm 0.85) \%$; the matrine in vivo blood vessels and skin probe recoveries were $(39.6 \pm 4.7) \%$ and $(41.1 \pm 1.7) \%$. The study was the first to clarify the topical oxymatrine after the percutaneous metabolism, the oxymatrine and its metabolite matrine dynamic metabolic process in the skin and blood. The microdiayisis sampling interval of $2 \mathrm{~min}$, the sampling of $5 \mu \mathrm{l}$, showed that it was very fast and efficient. The results revealed that due to the lower ability of metabolic enzymes oxymatrine on the skin, thus affecting the skin metabolism was much smaller than the body metabolism.

\section{Eye}

The application of the eye microdialysis could help us to obtain the drugs in ocular uptake, disposal and elimination of the data of drugs from the eye to improve the drug delivery system. The eye microdialysis method could overcome the long-term lack of the eye of the drug disposal problems. For the example, Waga et al. [103] found that the intraocular microdalysis probe permitted to prevent the short -term studies that affecting the in vitreous drug concentrations. Rittenhouse $\mathrm{KD}$ et al. [104] conducted the microdialysis method for determination in animal ocular given the B-blockers, propranolol drug concentration in aqueous humor and study the drug absorption and disposition in the eye. Other example like Anand et al. [105] facilitated the ocular MD method to study the validation process in rabbits with the implanted vitreous probes.

\section{Skeletal muscle}

Deleu et al. [106] used the microdialysis technique to study the carbidopa and entracapone effects of levodopa in plasma and skeletal muscle pharmacokinetics and metabolism, the results indicated that the carbidopa did not affect the levodopa plasma drug pharmacokinetic parameters, but increased the levodopa accumulation in skeletal muscle, therefore making the skeletal muscle performance in the extracellular fluid AUC and elimination half-life increased, this effect might be further strengthened by the entracapone. Hollenstein et al. [107] applied the microdialysis method to study the cefepime after the intravenous injection and infusion in skeletal muscle and subcutaneous tissue interstitial fluid in pharmacokinetics, the results had shown that after the intravenous infusion interstitial fluid concentrations were significantly higher than intravenous administration. Hereby, by this method could determine the antimicrobial drugs in the drug concentration at the target site and provided a good approach in the pharmacokinetic studies.

In the recent years, there are two articles $[108,109]$ reported using the microdialysis sampling combined with the traditional design method to predict the blood muscle tissue from the free drug concentration in plasma drug concentrations.

\section{Blood}

The samples can be collected free of proteins and long-term continuous sampling without loss of the body fluids from the vein during the microdialysis sampling process, therefore this technology has become the tremendous attention by the people. Martin TD et al. applied the microdialysis sampling combined with whole blood samples collected at the conscious, freedom of the research in mice after intravenous administration of theophylline, and found that the control group the specimens collected the elimination kinetics were affected by the quantity specimens and anesthesia impacts. While the microdialysis sampling and collecting the blood samples at the same time, there were no significant differences in the elimination halflife, only $(4.4 \pm 0.4) \mathrm{h}$, the microdialysis sampling individually results measured only $(3.0 \pm 0.4) \mathrm{h}$. The microdialysis method only determine the free drug concentration in plasma, when combined with the whole blood samples collected, the in vivo protein binding of the drug pharmacokinetic experiment can be studied. Other example like LV and his colleagues [110] conducted the combination of the on-line MD sampling and fluorescence detection for determination the ergometrine maleate pharmacokinetics in rabbit blood. Evrard et al. [111] designed a new microdialysis probe in mice and rats endovenous sampling, the retrodialysis method was used to determine the flurbiprofen recoveries and carry out the pharmacokinetic studies, the results concluded that the microdialysis technology was important in reducing the number of small laboratory animals in the pharmacokinetics and toxicokinetics analysis so as to improve the aspects of the quality of the collected data. In recent years, the microdialysis technology has been used in human intravenous pharmacokinetic studies, continuous monitoring the endogenous compounds or drugs in the blood concentration changes over time. Dethy et al. [112] conducted the microdialysis method coupled with the HPLC analysis to determine the advanced Parkinson's patients plasma levodopa and its metabolites concentrations, and found that the levodopa and its metabolites in vitro recovery detected was in the range of $22 \%-36 \%$. The levodopa dose and the levodopa dose in the blood plasma and its metabolites, homovanillic acid concentration had shown the significant positive correlation, the study found that the levodopa in the closed blood plasma average concentration was (7.74 $\pm 3.30) \mathrm{mmol} / \mathrm{L}$.

\section{Liver}

The microdialysis sampling can be used in a small amount of the animal to attain a more complete drug metabolism and pharmacokinetic data. Scott et al. [34] applied the microdialysis sampling to monitor the amino acid phenol sulfate and glucuronide metabolite concentrationtime behavior. The acetyl amino phenol was used to study the blood and liver pharmacokinetics of anesthetized mice. Kurata et al. used the microdiaysis method to determine the mouse liver and blood antipyrine concentration; the probe was buried into the mouse liver and right jugular vein. The antipyrine was intraperitoneally administrated with $50 \mathrm{mg} / \mathrm{kg}$. When the antipyrine at the two probes concentration in the dialysate and blood concentration collected from the jugular vein compared, from the serum, blood and liver dialysis solution obtained the elimination half-life were no significant differences, respectively with $2.2 \mathrm{~h}, 2.1 \mathrm{~h}$ and $2.1 \mathrm{~h}$. The microdialysis application in the mouse liver extracellular fluid can spend up to $48 \mathrm{~h}$ continuously sampling for determination of the drug concentrations. 


\section{Bile}

The bile microdialysis probe implanted into the bile duct can be used to monitor the normal animal's drug concentration [35]. After the drugs going through the liver metabolism process, then will pass through the bile duct for secretion. The bile duct secretion drugs included prototype drug and its metabolites. The bile duct drug determination not only can understand the drugs secretion conditions, but also can be used to study enterohepatic circulation. The microdialysis technology was applied in the bile duct pharmacokinetic studies and demonstrates that this bile microdialysis method will not affect the bile duct fluid loss and normal secretion, therefore can be long-term, continuously used to collect the determination the bile duct original unbound drugs and the metabolites [113-115].

\section{The pharmacokinetic study of the drugs excreted by the gallbladder}

Chang et al. $[115,116]$ used the HPLC analysis coupled with the online microdialysis technique to determine the rats bile duct unbound cefepine pharmacokinetics. The microdialysis probe was implanted into the bile duct, then injected the cefepine intravenously, according to the $50 \mathrm{mg} / \mathrm{kg}$ administration, the cefepine in the dialysate solution can be quantification determination. The inverting $\mathrm{C}_{18}$ column was applied in this study, maintaining the room optimum temperature, the mobile phase concentration was $100 \mathrm{~m} \mathrm{M}, \mathrm{p} \mathrm{H} 3.0$ of the sodium dihydrogen phosphate and methanol mixture, the ratio both of them were $87: 13$, the ultraviolet determination wavelength was $270 \mathrm{~nm}$. The results showed that the cefepine in the bile duct the elimination half-life was (64.01 \pm 9.32) $\min [117,118]$.

Tsai et al. [119] conducted the microdialysis probe and coupled with the automated on-line HPLC method to evaluate chloramphenicol and its glucuronide derivatives of the bile excretion microdialysis study. The microdialysis probe was implanted into the bile duct, then injected the chloramphenicol sodium succinate intravenously, according to 100 $\mathrm{mg} / \mathrm{kg}$ administration, the bile duct dialysate fluid could be collected and measured the unbound chloramphenicol and its glucuronide derivatives contents. In the pharmacokinetic study results indicated that the chloramphenicol in the bile duct process fulfilled the two-type model, while its glucuronide derivatives process fulfilled the singletype model. The bile duct chloramphenicol's glucuronide derivatives concentration was measured and found the AUC area concentrationtime was two times than chloramphenicol, thechloramphenicol's glucuronide derivatives bile duct excretion the elimination rate was significantly higher than chloramphenicol, suggesting that the chloramphenicol's glucuronide derivatives were majority excreted to the bile duct [118].

The bile microdialysis technique also can be applied in the pharmacokinetic studies of berberine by hepatobilliary excretion. The biologically active constituents berberine are isolated from the Genus Berberis or berberine roots and barks. Tsai et al. [119] combined the in vivo microdialysis technique with HPLC analysis to study the berberine pharmacokinetics and the hepatobiliary excretion mechanism. For the control group the rats only administrated with the berberine, before 10 minutes the co-treatment was injected the berberine, the P-glycoprotein inhibitor, yellow cyclosporine $\mathrm{A}$, organic cation transmitter and P-glycoprotein inhibitor Quinidine, cytochrome P450 inhibitor SKF$525 \mathrm{~A}$ and the glucuronidation formulation, probenecid. The results indicated that at the dose range from $10 \sim 20 \mathrm{mg} / \mathrm{kg}$, the berberine presented a linear pharmacokinetic phenomenon. When the berberine dose increased, the concentration-time AUC under the area would also enhanced [120]. Besides that, the berberine concentration from the hepatobilliary excretion was based on the ratio of berberine in the bile duct and blood. Because of the same dose administrated the berberine and yellow cyclosporine A or Quinidine $10 \mathrm{mg} / \mathrm{kg}$, the berberine main constituents might be affected by the P-glycoprotein and the organic cation transmitter, thus the berberine content significantly decreased. Apart from that, by using the HPLC and the ultraviolet analysis determination, the berberine in the liver metabolism mainly was due to the demethylation of the first phase and the glucuronidation of the second phase. As the co-treatment administrated with the SKF-525A, the berberine in the first phase reaction reduced, but in the second phase reaction-glucuronidation was not affected by the probenecid [121].

Furthermore, the bile microdialysis on-line coupled with the microbore liquid chromatography with fluorescence method for determination, measuring the rats bile duct unbound 20(S)camptothecin. The bile duct linear probe was implanted into the bile duct, then the microdialysates would be connected to the microbore liquid chromatography with fluorescence column. The sample used the mobile phase for elution. The mobile phase was methanol and the $100 \mathrm{~m}$ M sodium dihydrogen phosphate mixture, the ratio was 35:65, then used the phosphoric acid to adjust the $\mathrm{p} \mathrm{H}$ to 2.5 [122]. The camptothecin quantitative analysis content was $1 \mathrm{ng} / \mathrm{ml}$, then injected 5 $\mathrm{mg} / \mathrm{ml}$ camptothecin intravenously.

\section{The enterohepatic circulation drug pharmacokinetic study}

By using thehepato-duodenal shunt probe, to study the chloromycetin and its glucuronide derivatives in the enterohepatic process. In this study, the liver and duodenum probe was used, the drug treatment group donor rats the bile duct was connected to the bile cannula and non-treated rat duodenum receptors, to evaluate the pharmacokinetics of chloramphenicol dynamic applicationsthe liver metabolism and enterohepatic circulation. The unbound chloromycetin and its glucuronide derivatives the plasma blood concentration were determined by the on-line microdialysis method coupled with the microbore liquid chromatography. The results showed that the blood of the donor rats and the receptors rats, both of them also could measure the chloromycetin and its glucuronide derivatives, then the donor rats were injected chloramphenicol sodium succinate intravenously, according to the $100 \mathrm{mg} / \mathrm{kg}$ dose administration. The study found that, even though the enterohepatic circulation just only a small range (approximately 1.8\%) [123], but also participated in the unbound chloromycetin process and this study was suitable in the online microdialysis technique.

In addition to that, the bile microdialysis method can be used to study the effects of the bile salt absorption towards the caffeine and phenolphthalein glucoside. By comparing the caffeine and the phenolphalein glucoside both of the determination compound, suggesting that the micoridlaysis method could affect the bile salt reabsorption, the bile salt could react with the phenolphalein glucoside, but could not react with the caffeine. The results also implied that when the bile salt considered inside, the in vitro probe recovery correction could be used to measure the in vivo dialysates concentrations in the bile duct,via the in vitro recovery extraction efficiency correction phenolphthalein glucuronide concentration in the dialysate was consistent with the concentration measured in the bile in vivo. The results implied that by using the bile microdialysis probe, the caffeine extraction rate was higher than the phenolphthalein glucuronide, this phenomenon was not affected by the concentration and the bile salt. While the phenolphthalein glucuronide could react with the bile salt, the extraction rate in the bile salt was lower than 
the Ringer's solution. When the perfusate bile salt components were closely to the probe implanted the matrix components, the extraction rate was same as the recovery rate. The in vitro study suggesting that when the phenolphthalein glucuronide BSR concentration was in the range of $0.1 \sim 10 \mathrm{~m} \mathrm{M}$, the in vitro extraction rate was not affected by the concentration, but the repeatability was good, therefore was suitable applied in the in vivo analysis study. Besides that, the in vitro extraction used to correct the dialysate phenolphthalein glucuronide concentration was totally coincide with the directly measuring the bile duct sampling concentration.

\section{Kidney}

The kidney microdialysis technique is less topical application of the literature. Recently, Wang et al. [123] used the microdialysis sampling to study the anesthesia mice. After the mice were given the gludoPa, under the normal $1(0.28 \% \mathrm{NaCl}, \mathrm{NS})$ or high $(4 \% \mathrm{NaCl}, \mathrm{HS}) \mathrm{Na}$ balanced state, when they compared the renal interstitial fluid dopamine and the urine dopamine excretion, they found that the long-term $\mathrm{Na}$ load and quickly administrated the gludopa could stimulate the formation and release of dopamine into the renal tubules, the dopamine possessed the direct function in controlling the dopamine on the renal excretion. The renal effects of dopamine formation was not obviously regulated by the renal sympathetic nerve activity.

\section{Drug protein binding studies}

The microdialysis technique has been used to study the drug in vitro plasma protein binding, the experimental results are consistent with the traditional equilibrium dialysis and ultrafiltration assay results. The microdialysis method can be used to study the drug and plasma protein binding, because the sample volume constant during the study, the concentration of each component in the sample maintain essentially the same. In addition, due to the smaller probe membrane area, with the traditional separation of bound and free drug film and means compared to the non-specific adsorption of the drug on the membrane is less, therefore the measured results are more accurate. But however, during the in vitro analysis, due to ignore the metabolites and the parent drug the protein binding sites may exists the competition, so as the measured scores sometimes lower than the actual results in vivo. The in vitro binding sites of the drugs can be used in the unavailable anesthetized animal intravenous microdialysis in measuring the results and at the same time collecting the whole blood samples to carry out the in vivo drug binding studies to validate the results.

\section{The simultaneous multiple-probe in different organs studies}

Malhorta et al. [124] applied the simultaneous MD sampling method from the blood and brain to investigate the NMDA antagonist into the brain study. Tsai et al. [125] conducted the simultaneous MD sampling method from the bile duct and brain to evaluate and determine Genistein in soybeans the pharmacokinetics and metabolism study.

Next, we would like to further discuss the application of the microdialysis technique on-line coupled with the modernized analysis technology. Before that, we would briefly explain the factors affecting the on-line coupled application [125]. When applied the microdialysis on-line coupled with analysis, we need to take in account the probe recovery, perfusion rate, relative molecular weight analytes, such as the impact on the recovery of the probe, as well as analysis requires sensitivity volume, analyte concentration range, methods of sample and related factors limit the quantification, analysis speed and others. The probe absolute recovery reflects the degree of the interferences probes for biological dynamics of sampling sites. The higher the absolute recovery, the more material per unit time recovered and the interference of the tissue. In contrast, at low speed, less tissue recovered material, a more realistic concentrations in the reaction of the extracellular fluid, increasing the study reliability $[126,127]$. Therefore, in order to reduce the interference experiment of the tissue, selecting the appropriate perfusion rate was important. When the perfusion rate was small, the probe in vitro and in vivo solution had to spend much time to reach the equilibrium state; the absolute recovery rate would become increased. The traditional microdialysis perfusion rate was in the range of $0.5 \sim 2.0$ $\mu \mathrm{l} / \mathrm{min}$. The small particles the absolute recovery rate was normally in the range of $10 \% \sim 40 \%$, when the perfusion rate was $100 \mathrm{nl} / \mathrm{min}$, the absolute recovery rate was approximately $100 \%$.

The dialysate fluid volume is associated with the selected method of detection sensitivity instrument. When the perfusion rate was $1 \mu \mathrm{l} /$ $\mathrm{min}$, the sample concentration was $\mu \mathrm{mol} / \mathrm{L}$ degree, if the differentiation time was $1 \mathrm{~min}$, then the instrument determination was 1 pmol. If the determination was $10 \mathrm{pmol}$ or even high concentration, then the sample content need to be increased to $10 \mu \mathrm{l}$, the differentiation time extended to $10 \mathrm{~min}$.

Generally under the on-line combination application conditions, the time differentiation rate is closely-related to the analysis time As much as possible to get a complete chromatographic peak at the same time, we have to consider the maximum time to improve the microdialysis resolution. When the analysis time is longer than the changes continuously time, this changes can be reflected in the next sample. If the analysis time is shorter than the changes continuously time, then can be real-time for determination.

\section{New application in plants by microdialysis technology}

On the other hands, the microdialysis technology is also applied in the plants researches. For the example, Pretti et al. [128] developed a simple and rapid method for in vivo simultaneous determination of the ascorbic acid and antioxidant capacity in microdialysates from cladodes of Opuntia ficus-indica(L.) Miller by using the microdialysis technique. The method is verified in water-stressed plants, as compared with a well-watered test controls. The microdialysis probe construction and insertion procedure was specifically developed to minimize the tissue trauma of the plant and to obtain the optimal dialysis performance. MD was performed by applying a flow rate of $3 \mu \mathrm{l} / \mathrm{min}$ and the samples were analysed by HPLC coupled to the electrochemical detection of ascorbic acid and DPPH determined antioxidant capacity. The results indicated that the exponential decay of the concentrations of the analysed compounds as a function of microdialysis sampling time and found that the water-stressed Opuntia could decrease ascorbic acid levels and increased the other antioxidants.

Apart from that, the microdialysis sampling is presented as an in situ sampling and sample clean-up technique with the potential to be applied for determination of metals in plant suspension. Mosetlha et al. [129] conducted the microdialysis sampling to determine the $\mathrm{Cu}$ and $\mathrm{Ni}$ in plants by comparing the dialyzable metal fractions with total metal content. The suspensions prepared from ultra-pure water and flowers of a Blepharis aspera plant species obtained from a $\mathrm{Cu}$ and $\mathrm{Ni}$ mineralized site were sampled for $\mathrm{Cu}$ and $\mathrm{Ni}$ by microdialysis sampling after incorporating an optimal $0.05 \%(\mathrm{w} / \mathrm{v})$ composition of humic acid in the perfusion liquid. The acid digestion of the plant samples was employed for quantification of $\mathrm{Cu}$ and $\mathrm{Ni}$ by flame atomic absorption spectrometry. All microdialysis sampling studies were carried out at room temperature under quiescent conditions using a concentric type of microdialysis probe and the electrothermal atomic absorption 
spectrometry was employed for metal quantification. The versatility of the microdialysis as an in situ sampling and sample clean-up technique was demonstrated by the ability to sample $\mathrm{Cu}$ and $\mathrm{Ni}$ from the complex matrices of the plant suspensions. The linear relations between the concentrations of $\mathrm{Cu}$ and $\mathrm{Ni}$ determined after microdialysis sampling and acid digestion were established and the constant concentration ratios of the metals were found to be 0.0138 and 0.0440 respectively for $\mathrm{Cu}$ and $\mathrm{Ni}$, hence demonstrating the potential that microdialysis sampling has in prediction of metal concentrations in plant suspension after direct relation with the acid digestion method. Application of microdialysis in plants is very interesting for microdialysis new application. The differences about the vegetable tissue respect animals and the differences founded in the exponential decay in sampling, broaden a new challenge in probes materials and microdialysis technique.

\section{The Microdialysis Technique Coupled with the Newly- Modernized Analysis Technology On-line Application}

\section{The microdialysis technique coupled with HPLC on-line application}

The HPLC analysis is the acceptable method combined with the microdialysis system. The coupled applied in the system including HPLC pump, injector line, the column, detector and data processing systems. In the on-line injector can achieve the MD/HPLC combination core member. The traditional six-way injection valve needs to be split sample, and will lose some sample information. Steele et al. [130] compared the dual six-way valve and eight-way valve injector device, and found that both of them need to be split sample, no sample loss of the information, preferably for the drug pharmacokinetic studies, the reproducible injections eight-way valve is higher than the double six-way valve. Wang Dan et al. [131] established the microdialysis technique combined with the HPLC analysis and successfully applied this technique in transdermal drug delivery of the pharmacokinetics and metabolism study. The ten holes automatic injection valve was used, initially the dialysate fluid was stored in the dialysate loop, then by means of the electric power to be injected into the column. The loading platform can be continuously sequentially sample and the interval time in accordance with a predesigned injected in the HPLC system. By using this method can inspect simultaneously on more than two animals and also simultaneously connecting the two HPLC devices. This on-line device the precision, reproducibility and stability are superior than the offline devices. This is the first self-built and applied into the practical use in combination with online devices to promote this new technology widely applied in our foundation.

The type of the column used such as the length, particle size and others, is determined by the sampling interval desired and the required sensitivity. Only about $5 \sim 10 \mu \mathrm{l}$ sample are needed to carry out the LC assay. The short microbore columns have become famous for the microdialysis samples analysis because they provide the optimum combination of high sensitivity and rapid analysis. The column is basically used the capillary column and the microbore column with low flow rate, less dead volume, reducing the flow cell volume to avoid mixing and dispersion, and also reducing the peak broadening. The advantages of the microbores column are the injector sample volumes are less, can be low flow perfusion, reducing the dilution analytes and relatively increasing the detection limit. The HPLC-EC method can be applied the biogenic amines analysis [132], especially carried out the urine, blood, tissue and cerebrospinal fluid analysis. McLaughlin et al. [133] compared the microporous colum and conventional column for analysis the tirazepam, and found that the microporous column analysis time only $14 \mathrm{~min}$, the conventional column just only $23 \mathrm{~min}$, the analysis time was shortened. Mathy et al. [134] applied the microporous column to measure the blood and skin tissue the fluconazole, the analysis time was shortened from $40 \mathrm{~min}$ to $24 \mathrm{~min}$. The capillary columns are normally used in mass spectrometry, requires only small amount of the sample, helps the ionization mass spectrometry to improve the detection limits. Liu et al. [135] used the UPLC $2 \mu \mathrm{m}$ microporous column to determine the dialysate $5-\mathrm{HT}$, the sample had the peak within $1 \mathrm{~min}$, the sample content just need $500 \mathrm{nl}$ for analysis.

In the recent years, there are still a lot of the microbore systems applications for the microdialysis sample analysis. For the example, Yang et al. [136] and Verzele et al. [137] applied the microbore column packing miniaturation for the MD sampling analysis; Novotny $\mathrm{M}$ et al. [138] and Krejci et al. [139] applied the microcolumns in liquid chromatography analysis. Trisciani et al. [140] applied the microHPLC system to packed capillary column liquid chromatography to study the solvents delivery systems. Chaurasia et al. [141] used the MD-HPLC-ECD to monitor the conscious and freely moving rats the in vivo monoamine neurotransmitters and its metabolites contents changes. Yoshitake et al. [142] applied the MD-microbore column and carried out the HPLC-FL system, on-line post-column derivatization to determine the rat brain serotonin contents. Huang et al. [143] had developed a sensitive technique for determining the acetylcholine by using the microbore-LCEC and this technique just only preferably for the determination basal acetylcholine concentration. Andren and Caprioli have reported that by using the microdialysis with nanoflow capillary LC micro-ESI-MS [144] to detect the extracellular neurotensin release.

The most sensitivity for the analysis method is HPLC-MS. The MS as compared with the HPLC analysis has a great advantages: 1) the retention time and the molecular weight can be detected simultaneously; 2) the parent ions from the ion detector, providing a sensitive and efficient analysis; 3 ) the baseline drift the lowest,then the system could be quickly balanced( HPLC-ECD requires at least $24 \mathrm{~h}$ for the balance, as there is a slightly change will affect the fluctuation and need to be re-balanced); 4) reducing the retention time analysis. Shackman et al. [145] used the LC-MS to determine the acetyl-choline, the analysis was just only 8 amol.

\section{On-line analysis microdialysis-CE}

The HPCE possess the trace, high efficiency and high-resolution characteristics, the HPCE sample injection volume requires 1 10 $\mathrm{nl}$, but low requirements for the sample pretreatment, can be used to isolate a very amount of the sample to obtain the high separation efficiency rate $(\geq 1000000 / \mathrm{m})$ [146]. When using the HPLC the sample separation rate is totally poor, especially applied for the chiral sample, the CE method is often possible to obtain satisfactory separation rate. The CE development and its microdialysis technique application has reported its literatures reviewed $[147,148]$. The quantification detection of the available capacity CE preconcentration sample( concentration or conventional extraction) or a high sensitivity detection method such as lase-mediated fluorescence (LIF), MS/ESI, MALDI-TOF, ECD and other combination to strengthen its application.

The MD-CE online is an important factor associated with the sampling interface. The early article reported this on-line analysis combination application was such that Hogan et al. [149] applied the nanoliter injection valve as the interface, the dialysate was collected into the sample loop, using the special transfer line to transfer the 
sample from the injection valve to the inlet of the separation capillary, this system was successfully applied in the anti-tumor agents in blood studies. The quite similar system [149] approached in applying the online NDA/CN derivatives to monitor the brain in vivo aspartate and glutamate release study. Zhou et al. [150,151] established the MD-CEECD system to monitor the nicotine transdermal drug delivery system. The carbon fiber working electrode and the capillary wave loaded with cellulose acetate were used to avoid the effects of high pressure on the animals, continuously monitoring the nicotine transdermal patch within $24 \mathrm{~h}$ the endothelial skin concentration, the study time resolution was only $10 \mathrm{~min}$.

Lada et al. [152] used the injection flow rate control interface instead of the injection valve to achieve the injection sampling process, the interface could reduce the perfusion rate, the time resolution was in the range of $65 \sim 85 \mathrm{~s}$, successfully carried out the brain in vivo various types of the neurotransmitters separation and quantitative analysis. Browser and Kennedy [153] designed the sheath flow cell system by reducing the fluorescence background and the scattered laser shot was used to increase the sensitivity (15 times), successfully achieved the amine separation. Li et al. [154] applied the microdialysis sampling method, the CE-LIF method was conducted to measure the dialysates various types of the amino acids levels changes, the time resolution was $15 \mathrm{~s}$ and thus predicting its real-time monitoring characteristic. Shou $M$ et al. [155] established the microdialysis-micellar electrokinetic chromatography-LIF online monitoring the rats brain dopamine concentration changes, the detection limit of $2 \mathrm{nmol} / \mathrm{L}$, the striated body baseline dopamine concentration was $(18 \pm 3) \mathrm{nmol} / \mathrm{L}(\mathrm{n}=12)$. This method not only could accurately measure the striated body baseline dopamine concentration, but also could effectively determine after the codeine administration the dopamine levels and the behavior changes. But the electrophoresis could be detected about 60 multiple peaks, suggesting that the method could be used to determine the various in vivo substances changes.

Other examples of the on-line microdialysis analysis-CE such as Rada et al. [156] conducted the micellar electrokinetic chromatography and laser-induced fluorescence detection to monitor the gammaaminobutyric acid in human brain and plasma microdialysates. Besides that, Park et al. [157] and Qian et al. [158] conducted the CEEC for dopamine detection in the microdialysates samples.

There are also some reports had revealed the CE-MS for the microdialysis samples analysis. For the example, Takada et al. [159] applied the in vivo microdialysis-capillary electrophoresis/MS to detect the gamma-aminobutyric acid in a living rat brain. Zhang et al. [160] applied the combination of the solid-phase preconcentration, capillary electrophoresis and off-line matrix-assisted laser desorption/ionization mass spectrometry to study the peptide $\mathrm{E}$ in vivo intracerebral metabolism process.

\section{Microdialysis and in combination with other analytical techniques online}

The microchip electrophoresis is a spectrometer developed in recent years. The derivatized samples can be done on the chip, the sample size is required only $\mathrm{nl} \sim \mathrm{pl}$, quick analysis, the detector can be integrated into the chip, easy to implement the miniaturization system. The online connection the major challenges is that we can collect the analysis of piping dialysate chips and fast, efficiently by using the on-line automatic analysis method to obtain the results. Huyhn et al. [161] was first time proposed this combination method, which was designed from the soda lime glass by the T-dual welded channel, the micro tight was used to connect the microdialysis and chips system. By controlling the injection gate, the microdialysis samples were segmented into the electrophoretic separation channel for analysis and this method was successfully used in monitoring the beta-glucosidase activity. Sandlin et al. [162] used the precolumn OPA derivatives, LIF analysis to measure the anesthesia rats in vivo amino acid contents. The Upchruch fitting which was connected with the capillaries (for connecting the probe outlet) and chips, gated continuously monitoring the injection procedure, the time resolution was in the range of $2 \sim 4 \mathrm{~min}$.

The biosensor system combined with the microdialysis technique of the main part was the enzyme electrode. This main part could specifically react with the dialysate and could be determined by the detector to achieve the real-time analysis and determination. Since the conventional sensors based on the principle of non-separation, thus usually only preferably used for the substances testing. Toshio Yao et al. [163] established the six automatic switching the injection valve flow injection sensors systems, including the three enzymes electrode detector, online real-time continuously determination of a variety of neurological rat brain neurotransmitters.

Other examples had shown the biosensors combined with the microdialysis technique such as Zilka et al. [164] used the on-line microdialysis coupled with the enzyme-amperometric analysis for monitoring the in vivo L-glutamate concentration accompanying by the cardiac arrest and $\mathrm{K}+$-induced the local depolarization. Volpe G et al. [165] used the microdialysis and electrochemical biocell to monitor the in vivo continuous of L-lactate subcutaneous tissues of humans and rabbits.

\section{Conclusions and Future Perspective Directions}

The microdialysis combined with the modern analytical techniques for detection possess the obvious advantages rather than other sampling technique in endogenous and exogenous substances real-time detection of various drugs in all the areas. The sampling operation can significantly reduce the impact of the normal state of the experiments animals, such as measured results closest to the true state of the measured substances in the body; continuously real-time sampling and enables real-time detection and clearly measuring the in vivo changing substances in the same individual process; eliminates the sample pre-treatment process to reduce the impact of the external operation of the sample and to avoid the waste of the sample and finally the high sensitivity of modern analytical techniques to ensure the reliability of the test results.

At present, the domestic application for the microdialysis technique just limited primarily to the off-line and modern analysis techniques combined with the analytical applications, majority applied in the measuring the animals neurotransmitters studies [166], but in the distribution of drugs and metabolic dynamics and as the application of the administration or application of treatment rarely reported. Due to limitations of the dialysis membrane probe, there are still some limitations of the technology application in the macromolecules and fatsoluble. Commercialization of the online instruments associated with the higher cost due to this technology application limits our country using this technology. Additionally, the microdialysis technique itself requires a high demand operation, the high commodity costs also restrict the probe technique factors applied in various fields.

As a conclusion, we all just need to take full advantage of the strengths and deficiencies microdialysis technique, applicability and shortcomings, then only properly design the study, wisely selecting the sampling methods to avoid detours. 
Citation: Lee MKK, Di L (2014) Crosstalk the Microdialysis in Scientific Research: from Principle to its Applications. Pharm Anal Acta 5: 276. doi: $10.4172 / 2153-2435.1000276$

Page 17 of 20

\section{Acknowledgement}

The authors were truly grateful to Prof. Dilq and Prof. Cai Baochang for technical assistance. This work was financially supported by the Priority Academic Program Development of Jiangsu Higher Education Institutions (No.2011ZYX3001), Qing Lan Project of Jiangsu Province(No.200806).All authors had full access to all the data in the study and took responsibility for the integrity of the data and the accuracy of the data analysis. The content is solely the responsibility of the authors and does not neccesarily represent the official reviews of the Priority Academic Program Development of Jiangsu Higher Education Institutions.

\section{References}

1. Spanagel R, Eilbacher B, Wilke R (1994) Memantine-induced dopamine release in the prefrontal cortex and striatum of the rat--a pharmacokinetic microdialysis study. Eur J Pharmacol 262: 21-26.

2. Beier H, Kaiser K, Langhans M, Malmendier K, Sluijsmans I, et al. (2007) Peritoneal microdialysis in freely moving rodents: an alternative to blood sampling for pharmacokinetic studies in the rat and the mouse. Eur J Pharm Sci 30: 75-83.

3. Hamberger A, Jacobson I, Nyström B, Sandberg M (1991) Microdialysis sampling of the neuronal environment in basic and clinical research. J Intern Med 230: 375-380.

4. Gaddum JH(1961) Push -pull cannule .J Physiol155:1-2

5. Bito L, Davson H, Levin E, Murray M, Snider N (1966) The concentrations of free amino acids and other electrolytes in cerebrospinal fluid, in vivo dialysate of brain, and blood plasma of the dog. J Neurochem 13: 1057-1067.

6. Delgado JM, DeFeudis FV, Roth RH, Ryugo DK, Mitruka BM (1972) Dialytrode for long term intracerebral perfusion in awake monkeys. Arch Int Pharmacodyn Ther 198: 9-21.

7. Ungerstedt $U$, Ljungberg $T$ (1974) Central dopamine neurons and sensory processing. J Psychiatr Res 11: 149-150.

8. Blöchl-Daum B, Müller M, Meisinger V, Eichler HG, Fassolt A, et al. (1996) Measurement of extracellular fluid carboplatin kinetics in melanoma metastases with microdialysis. Br J Cancer 73: 920-924.

9. Causon R (1997) Validation of chromatographic methods in biomedical analysis. Viewpoint and discussion. J Chromatogr B Biomed Sci Appl 689: 175180.

10. Anderson C, Andersson T, Molander M (1991) Ethanol absorption across human skin measured by in vivo microdialysis technique. Acta Derm Venereol 71: 389-393.

11. Cross SE, Anderson C, Roberts MS (1998) Topical penetration of commercial salicylate esters and salts using human isolated skin and clinical microdialysis studies. Br J Clin Pharmacol 46: 29-35.

12. Ståhle L (1992) Pharmacokinetic estimations from microdialysis data. Eur $J$ Clin Pharmacol 43: 289-294.

13. Hsiao JK, Ball BA, Morrison PF, Mefford IN, Bungay PM (1990) Effects of different semipermeable membranes on in vitro and in vivo performance of microdialysis probes. J Neurochem 54: 1449-1452.

14. Sjögren F, Svensson C, Anderson C (2002) Technical prerequisites for in vivo microdialysis determination of interleukin- 6 in human dermis. $\mathrm{Br} \mathrm{J}$ Dermatol 146: 375-382.

15. William FE, Ronald JS (1997) Application of MD in PK studies. Pharm Rres 14:167-288

16. Chaurasia CS, Müller M, Bashaw ED, Benfeldt E, Bolinder J, et al.(2007) AAPS-FDA Workshop White Paper: Microdialysis Principles, Application and Regulatory Perspectives. Pharm Res 24: 1014-1025.

17. Telting-Diaz M, Scott DO, Lunte CE (1992) Intravenous microdialysis sampling in awake, freely-moving rats. Anal Chem 64: 806-810.

18. Zetterström T, Sharp T, Marsden CA, Ungerstedt U (1983) In vivo measurement of dopamine and its metabolites by intracerebral dialysis: changes after d-amphetamine. J Neurochem 41: 1769-1773.

19. Davies MI (1999) A review of MD sampling for pharmacokinetic applications. Anal Chim Acta 379: 227-249.

20. Hughes PM, Krishnamoorthy R, Mitra AK (1996) Vitreous disposition of two acycloguanosine antivirals in the albino and pigmented rabbit models: a nove ocular microdialysis technique. J Ocul Pharmacol Ther 12: 209-224.
21. Ungerstedt U, Pycock C (1974) Functional correlates of dopamine neurotransmission. Bull Schweiz Akad Med Wiss 30: 44-55

22. Zuo H,Ye M, Davies MI (1995) The linear probe: a flexible choice for in vivo microdialysis sampling in soft tissues. Curr Sep 14: 54-57.

23. Ault JM, Lunte CE, Meltzer NM, Riley CM (1992) Microdialysis sampling for the investigation of dermal drug transport. Pharm Res 9: 1256-1261.

24. Ault JM, Riley CM, Meltzer NM, Lunte CE (1994) Dermal microdialysis sampling in vivo. Pharm Res 11: 1631-1639.

25. Zuo H, Ye M, Davies MI(1996) Monitoring transdermal delivery of nicotine using in vivo microdialysis sampling. Curr Sep 15: 63-66.

26. Palsmeier RK, Lunte CE (1994) Microdialysis sampling in tumor and muscle: study of the disposition of 3-amino-1,2,4-benzotriazine-1,4-di-N-oxide (SR 4233). Life Sci 55: 815-825.

27. Shah KP, Chang M, Riley CM (1994) Automated analytical systems for drug development studies. Il--A system for dissolution testing. J Pharm Biomed Ana 12: $1519-1527$.

28. Shah KP, Chang M, Riley CM (1995) Automated analytical systems for drug development studies.3.Multivessel dissolution testing system based on microdialysis sampling, J Pharm Biomed Anal13:1235-1241.

29. Gunaratna C, Kissinger PT (1997) Application of microdialysis to study the in vitro metabolism of drugs in liver microsomes. J Pharm Biomed Anal 16: 239 248.

30. Gunaratna C, Kissinger PT (1998) Investigation of stereoselective metabolism of amphetamine in rat liver microsomes by microdialysis and liquid chromatography with precolumn chiral derivatization. J Chromatogr A 828: 95103.

31. Zhou J, Shearer EC, Hong J, Riley CM, Schowen RL (1996) Automated analytical systems for drug development studies. V. A system for enzyme kinetic studies. J Pharm Biomed Anal 14: 1691-1698.

32. Knaub SR, Chang MF, Lunte CE, Topp EM, Riley CM (1995) Automated analytical systems for drug development studies. Part IV. A microdialysis system to study the partioning of the lomefloxacin across an erythrocyte membrane in vitro. J Pharm Biomed Anal14:121-129.

33. Torto N, Buttler T, Gorton L, Marko-Varga G, Stalbrand H ,Tjerneld F (1995) Monitoring of enzymatic hydrolysis of ivory nut mannan using on-line microdialysis sampling and anion-exchange chromatography with integrated pulsed electrochemical detection. Anal Chim Acta 313:15-24

34. Scott DO, Lunte CE (1993) In vivo microdialysis sampling in the bile, blood, and liver of rats to study the disposition of phenol. Pharm Res 10: 335-342.

35. Gunaratna C, Lunte SM, Zuo H(1994) Shunt probe: a new microdialysis probe design for in vivo drug metabolism studies, Curr Sep:1380-1383.

36. Hadwiger ME, Telting-Diaz M, Lunte CE (1994) Liquid chromatographic determination of tacrine and its metabolites in rat bile microdialysates. $J$ Chromatogr B Biomed Appl 655: 235-241.

37. Heppert KE, Davies MI (1999) Using a microdialysis shunt probe to monito phenolphthalein glucuronide in rats with intact and diverted bile flow. Anal Chim Acta 379: 359-366.

38. Lönnroth P, Jansson PA, Smith U (1987) A microdialysis method allowing characterization of intercellular water space in humans. Am J Physiol 253 E228-231.

39. Olson RJ, Justice JB Jr (1993) Quantitative microdialysis under transient conditions. Anal Chem 65: 1017-1022.

40. Wang Y, Wong SL, Sawchuk RJ (1993) Microdialysis calibration using retrodialysis and zero-net flux: application to a study of the distribution of zidovudine to rabbit cerebrospinal fluid and thalamus. Pharm Res 10: 14111419

41. Stahl M, Bouw R, Jackson A, Pay V (2002) Human microdialysis. Curr Pharm Biotechnol 3: 165-178.

42. Larsson $\mathrm{Cl}$ (1991) The use of an "internal standard" for control of the recovery in microdialysis. Life Sci 49: PL73-78.

43. Wang Y, Wong SL, Sawchuk RJ (1991) Comparision of in vivo and in vitro calibration of microdialusis probes using retrodialysis $10: 87$.

44. de la Peña A, Liu P, Derendorf H (2000) Microdialysis in peripheral tissues. Adv Drug Deliv Rev 45: 189-216. 
Citation: Lee MKK, Di L (2014) Crosstalk the Microdialysis in Scientific Research: from Principle to its Applications. Pharm Anal Acta 5: 276. doi: $10.4172 / 2153-2435.1000276$

45. Fulzele SV, Babu RJ, Ahaghotu E, Singh M (2007) Estimation of proinflammatory biomarkers of skin irritation by dermal microdialysis following exposure with irritant chemicals. Toxicology 237: 77-88.

46. Morgan ME, Singhal D, Anderson BD (1996) Quantitative assessment of bloodbrain barrier damage during microdialysis. J Pharmacol Exp Ther 277: 11671176.

47. Anderson JM, Rodriguez A, Chang DT (2008) Foreign body reaction to biomaterials. Semin Immunol 20: 86-100.

48. Di Chiara G, Tanda G, Carboni E (1996) Estimation of in-vivo neurotransmitter release by brain microdialysis: the issue of validity. Behav Pharmacol 7: 640657

49. Westerink BH, Damsma G, Rollema H, De Vries JB, Horn AS (1987) Scope and limitations of in vivo brain dialysis: a comparison of its application to various neurotransmitter systems. Life Sci 41: 1763-1776.

50. Gifford R, Kehoe JJ, Barnes SL, Kornilayev BA, Alterman MA, et al. (2006) Protein interactions with subcutaneously implanted biosensors. Biomaterials 27: $2587-2598$

51. Dungel P, Long N, Yu B, Moussy Y, Moussy F (2008) Study of the effects of tissue reactions on the function of implanted glucose sensors. J Biomed Mater Res A 85: 699-706.

52. Koschwanez HE, Reichert WM (2007) In vitro, in vivo and post explantation testing of glucose-detecting biosensors: current methods and recommendations. Biomaterials 28: 3687-3703.

53. Parsons LH, Justice JB Jr (1994) Quantitative approaches to in vivo brain microdialysis. Crit Rev Neurobiol 8: 189-220.

54. Desrayaud S, Guntz P, Scherrmann JM, Lemaire M (1997) Effect of the P-glycoprotein inhibitor, SDZ PSC 833, on the blood and brain pharmacokinetics of colchicine. Life Sci 61: 153-163.

55. Xie R, Hammarlund-Udenaes M (1998) Blood-brain barrier equilibration of codeine in rats studied with microdialysis. Pharm Res 15: 570-575.

56. Graff CL, Pollack GM (2005) Nasal drug administration: potential for targeted central nervous system delivery. J Pharm Sci 94: 1187-1195.

57. Illum L (2000) Transport of drugs from the nasal cavity to the central nervous system. Eur J Pharm Sci 11: 1-18.

58. Illum L (2002) Nasal drug delivery: new developments and strategies. Drug Discov Today 7: 1184-1189.

59. Feng J, Li F, Zhao Y, Feng Y, Abe Y (2009) Brain pharmacokinetics of tetramethylpyrazine after intranasal and intravenous administration in awake rats. Int J Pharm 375: 55-60.

60. Samuelsson C, Kumlien E, Elfving A, Lindholm D, Ronne-Engström E (2003) The effects of PBN (phenyl-butyl-nitrone) on GLT-1 levels and on the extracellular levels of amino acids and energy metabolites in a model of ironinduced posttraumatic epilepsy. Epilepsy Res 56: 165-173.

61. Shalev U, Grimm JW, Shaham Y (2002) Neurobiology of relapse to heroin and cocaine seeking: a review. Pharmacol Rev 54: 1-42.

62. Swanson CJ, Schoepp DD (2003) A role for noradrenergic transmission in the actions of phencyclidine and the antipsychotic and antistress effects of mGlu2/3 receptor agonists. Ann N Y Acad Sci 1003: 309-317.

63. Berger C, Dohmen C, Maurer MH, Graf R, Schwab S (2004) [Cerebral microdialysis in stroke]. Nervenarzt 75: 113-123.

64. Kimelberg HK, Nestor NB, Feustel PJ (2004) Inhibition of release of taurine and excitatory amino acids in ischemia and neuroprotection. Neurochem Res 29: $267-274$

65. Lin JY, Chung SY, Lin MC, Cheng FC (2002) Effects of magnesium sulfate on energy metabolites and glutamate in the cortex during focal cerebral ischemia and reperfusion in the gerbil monitored by a dual-probe microdialysis technique. Life Sci 71: 803-811.

66. Maurer MH, Berger C, Wolf M, Fütterer CD, Feldmann RE Jr,et al.(2003)The proteome of human brain micro- dialysate.Proteome Sic 1:7.

67. Berger C, Schäbitz WR, Georgiadis D, Steiner T, Aschoff A, et al. (2002) Effects of hypothermia on excitatory amino acids and metabolism in stroke patients: a microdialysis study. Stroke 33: 519-524.

68. Chou YT, Lin MT, Lee CC, Wang JJ (2003) Hypothermia attenuates cerebral dopamine overloading and gliosis in rats with heatstroke. Neurosci Lett 336 $5-8$
69. Tettey-Amlalo RN, Kanfer I, Skinner MF, Benfeldt E, Verbeeck RK (2009) Application of dermal microdialysis for the evaluation of bioequivalence of a ketoprofen topical gel. Eur J Pharm Sci 36: 219-225.

70. Mathy FX, Ntivunwa D, Verbeeck RK, Préat V (2005) Fluconazole distribution in rat dermis following intravenous and topical application: a microdialysis study. J Pharm Sci 94: 770-780.

71. Brunner M, Dehghanyar P, Seigfried B, Martin W, Menke G, et al. (2005) Favourable dermal penetration of diclofenac after administration to the skin using a novel spray gel formulation. Br J Clin Pharmacol 60: 573-577.

72. Patel S, Shukla C, Patel G, Stagni G (2010) Pharmacokinetics of amitriptyline in rabbit skin and plasma following iontophoretic administrations. Drug Dev Ind Pharm 36: 379-384.

73. Höcht C, Opezzo JA, Bramuglia GF, Taira CA (2006) Application of microdialysis in clinical pharmacology. Curr Clin Pharmacol 1: 163-183.

74. García Ortiz P, Hansen SH, Shah VP, Sonne J, Benfeldt E (2011) Are marketed topical metronidazole creams bioequivalent? Evaluation by in vivo microdialysis sampling and tape stripping methodology. Skin Pharmacol Physiol 24: 44-53.

75. Benfeldt E, Hansen SH, Vølund A, Menné T, Shah VP (2007) Bioequivalence of topical formulations in humans: evaluation by dermal microdialysis sampling and the dermatopharmacokinetic method. J Invest Dermatol 127: 170-178.

76. Patlolla RR, Mallampati R, Fulzele SV, Babu RJ, Singh M (2009) Dermal microdialysis of inflammatory markers induced by aliphatic hydrocarbons in rats. Toxicol Lett 185: 168-174.

77. Scherer PE (2006) Adipose tissue: from lipid storage compartment to endocrine organ. Diabetes 55: 1537-1545.

78. Dostálová I, Kopský V, Dusková J, Papezová H, Pacák K, et al. (2005) Leptin concentrations in the abdominal subcutaneous adipose tissue of patients with anorexia nervosa assessed by in vivo microdialysis. Regul Pept 128: 63-68.

79. Dostálová I, Kaválková P, Haluzíková D, Housová J, Matoulek M, et al. (2009) The use of microdialysis to characterize the endocrine production of human subcutaneous adipose tissue in vivo. Regul Pept 155: 156-162.

80. Sun N, Wen J, Lu G, Hong Z, Fan G, et al. (2010) An ultra-fast LC method for the determination of iodiconazole in microdialysis samples and its application in the calibration of laboratory-made linear probes. J Pharm Biomed Anal 51 : 248-251.

81. Gao S, Tao X, Sun L, Sheng C, Zhang W, et al. (2009) An liquid chromatographytandem mass spectrometry assay for determination of trace amount of new antifungal drug iodiconazole in human plasma. J Chromatogr B Analyt Techno Biomed Life Sci 877: 382-386.

82. Haderer A, Gerner P, Kao G, Srinivasa V, Wang GK (2003) Cutaneous analgesia after transdermal application of amitriptyline versus lidocaine in rats. Anesth Analg 96: 1707-1710, table of contents.

83. Shukla C, Friden P, Juluru R, Stagni G (2009) In vivo quantification of acyclovir exposure in the dermis following iontophoresis of semisolid formulations. Pharm Sci 98: 917-925.

84. Ortiz PG, Hansen SH, Shah VP, Menné T, Benfeldt E (2008) The effect of irritant dermatitis on cutaneous bioavailability of a metronidazole formulation, investigated by microdialysis and dermatopharmacokinetic method. Contact Dermatitis 59: $23-30$

85. Garcia Ortiz P, Hansen SH, Shah VP, Menné T, Benfeldt E (2009) Impact of adult atopic dermatitis on topical drug penetration: assessment by cutaneous microdialysis and tape stripping. Acta Derm Venereol 89: 33-38.

86. Traunmüller F, Schintler MV, Spendel S, Popovic M, Mauric O, et al. (2010) Linezolid concentrations in infected soft tissue and bone following repetitive doses in diabetic patients with bacterial foot infections. Int J Antimicrob Agents 36: 84-86.

87. Traunmüller F, Zeitlinger M, Zeleny P, Müller M, Joukhadar C (2007) Pharmacokinetics of single- and multiple-dose oral clarithromycin in soft tissues determined by microdialysis. Antimicrob Agents Chemother 51: 3185-3189.

88. Engleman EA, Ingraham CM, Franklin KM, Keith CM, McClaren JA, et al. (2008) In vivo time-course changes in ethanol levels sampled with subcutaneous microdialysis. Alcohol Clin Exp Res 32: 435-442.

89. Shukla C, Patel V, Juluru R, Stagni G (2009) Quantification and prediction of skin pharmacokinetics of amoxicillin and cefuroxime. Biopharm Drug Dispos 30: 281-293. 
90. Eberle T, Doganci B, Krämer H, Fechir M, Wagner I, et al. (2010) Mechanical but not painful electrical stimuli trigger TNF alpha release in human skin. Exp Neurol 221: 246-250.

91. Wiswedel I (2009) F(2)-isoprostanes: sensitive biomarkers of oxidative stress in vitro and in vivo: a gas chromatography-mass spectrometric approach. Methods Mol Biol 580: 3-16.

92. Sjögren F, Anderson C (2009) Sterile trauma to normal human dermis invariably induces IL1beta, IL6 and IL8 in an innate response to "danger". Acta Derm Venereol 89: 459-465.

93. Petersen LJ, Pedersen JL, Skov PS, Nielsen HJ, Kehlet H (2009) Histamine is not released in acute thermal injury in human skin in vivo: a microdialysis study. Inflamm Res 58: 395-399.

94. Paterson S, Schmelz M, McGlone F, Turner G, Rukwied R (2009) Facilitated neurotrophin release in sensitized human skin. Eur J Pain 13: 399-405.

95. Shinkai N, Korenaga K, Takizawa H, Mizu H, Yamauchi H (2008) Percutaneous penetration of felbinac after application of transdermal patches: relationship with pharmacological effects in rats. J Pharm Pharmacol 60: 71-76.

96. Shinkai N, Korenaga K, Mizu H, Yamauchi H (2008) Intra-articular penetration of ketoprofen and analgesic effects after topical patch application in rats. $J$ Control Release 131: 107-112.

97. Brazís P, Barandica L, García F, Clough GF, Church MK, et al. (2006) Derma microdialysis in the dog: in vivo assessment of the effect of cyclosporin A on cutaneous histamine and prostaglandin D2 release. Vet Dermatol 17: 169-174.

98. Hubing KA, Wingo JE, Brothers RM, Del Coso J, Low DA, et al.(2010) Nitric oxide synthase inhibition attenuates cutaneous vasodilation during postmenopausal hot flash episodes . Menopause 17:978-982.

99. Zhang YF, Yu Yang, Zhou LL (2010) Microdialysis technique combined with isotope tracer method performed Sinomenine skin patch dynamics of local pharmacokinetics. Chinese Journal of Experimental Traditional Medical Formulae 16:147.

100.Wang D, Shi LF, Hu JH (2008)Microdialysis combined with HPLC method to determine puerarin on rat skin pharmacokinetics study. Analytical Chemistry 36:1391.

101.Zhang QL, Hu JH, Zhu QG, Li FQ, Liu JY, et al. (2009) Development of a novel HPLC-MS/MS method for the determination of aconitine and its application to in vitro and rat microdialysis samples. Biomed Chromatogr 23: 692-699.

102.Zheng H, Chen G, Shi L, Lou Z, Chen F, et al. (2009) Determination of oxymatrine and its metabolite matrine in rat blood and dermal microdialysates by high throughput liquid chromatography/tandem mass spectrometry. J Pharm Biomed Anal 49: 427-433.

103. Waga J, Ohta A, Ehinger B (1991) Intraocular microdialysis with permanently implanted probes in rabbit. Acta Ophthalmol (Copenh) 69: 618-624.

104. Rittenhouse KD, Peiffer RL Jr, Pollack GM (1998) Evaluation of microdialysis sampling of aqueous humor for in vivo models of ocular absorption and disposition. J Pharm Biomed Anal 16: 951-959.

105. Anand BS, Atluri H, Mitra AK (2004) Validation of an ocular microdialysis technique in rabbits with permanently implanted vitreous probes: systemic and intravitreal pharmacokinetics of fluorescein. Int J Pharm 281: 79-88.

106. Deleu D, Sarre S, Ebinger G, Michotte $Y$ (1995) The effect of carbidopa and entacapone pretreatment on the L-dopa pharmacokinetics and metabolism in blood plasma and skeletal muscle in beagle dog: an in vivo microdialysis study. J Pharmacol Exp Ther 273: 1323-1331.

107. Hollenstein U, Brunner M, Mayer BX, Delacher S, Erovic B, et al. (2000) Targe site concentrations after continuous infusion and bolus injection of cefpirome to healthy volunteers. Clin Pharmacol Ther 67: 229-236.

108. Nolting A, Costa TD, Vistelle R, Rand KH, Derendorf H (1996) Determination of free extracellular concentrations of piperacillin by microdialysis. J Pharm Sci 85: 369-372.

109. Kovar A, Dalla Costa T, Derendorf H (1997) Comparison of plasma and free tissue levels of ceftriaxone in rats by microdialysis. J Pharm Sci 86: 52-56.

110. Lv Y, Zhang Z, Gong Z, Hu Y, He D (2005) Determination and pharmacokinetics of ergometrine maleate in rabbit blood with on line microdialysis sampling and fluorescence detection. J Pharm Biomed Anal 38: 29-33.

111. Evrard PA, Deridder G, Verbeeck RK (1996) Intravenous microdialysis in the mouse and the rat: development and pharmacokinetic application of a new probe. Pharm Res 13: 12-17.
112. Dethy S, Laute MA, Van Blercom N, Damhaut P, Goldman S, et al. (1997) Microdialysis-HPLC for plasma levodopa and metabolites monitoring in parkinsonian patients. Clin Chem 43: 740-744.

113. Tsai TH, Wu JW (2003) Regulation of hepatobiliary excretion of sinomenine by P-glycoprotein in Sprague-Dawley rats. Life Sci 72: 2413-2426.

114. Chan YL, Chou MH, Lin MF, Chen CF, Tsai TH (2002) Determination and pharmacokinetic study of meropenem in rat bile using on-line microdialysis and liquid chromatography. J Chromatogr A 961: 119-124.

115. Chang YL, Chou MH, Lin MF, Chen CF, Tsai TH (2001) Determination and pharmacokinetic study of unbound cefepime in rat bile by liquid chromatography with on-line microdialysis. J Chromatogr A 914: 77-82.

116. Chang YL, Chiou SH, Chou YC, Yen CJ, Tsai TH (2007) Quantitative determination of unbound cefoperazone in rat bile using microdialysis and liquid chromatography. J Pharm Biomed Anal 45: 158-163.

117. Liu SC, Tsai TH (2002) Determination of diclofenac in rat bile and its interaction with cyclosporin A using on-line microdialysis coupled to liquid chromatography. J Chromatogr B Analyt Technol Biomed Life Sci 769: 351-356.

118. Tsai TH, Hung LC, Chen CF (1999) Microdialysis study of biliary excretion of chloramphenicol and its glucuronide in the rat. J Pharm Pharmacol 51: 911 915.

19. Tsai $\mathrm{Pi}$, Tsai TH (2002) Simultaneous determination of berberine in rat blood, liver and bile using microdialysis coupled to high-performance liquid chromatography. J Chromatogr A 961: 125-130.

120. Tsai PL, Tsai TH (2004) Hepatobiliary excretion of berberine. Drug Metab Dispos 32: 405-412.

121. Tsai TH, Tsai TR, Chen YF, Chou CJ, Chen CF (1999) Determination of unbound 20(S)-camptothecin in rat bile by on-line microdialysis coupled to microbore liquid chromatography with fluorescence detection. J Chromatogr $B$ Biomed Sci Appl 732: 221-225.

122. Tsai TH, ShumAY, Chen CF (2000) Enterohepatic circulation of chloramphenicol and its glucuronide in the rat by microdialysis using a hepato-duodenal shunt. Life Sci 66: 363-370.

123. Wang ZQ, Siragy HM, Felder RA, Carey RM (1997) Intrarenal dopamine production and distribution in the rat. Physiological control of sodium excretion. Hypertension 29: 228-234

124. Malhotra B, Lemaire M, Brouillard J, Sawchuk R (1996) High performance liquid chromatographic analysis of (S)-?-amino-5-ph-osphonomethyl[1,1'biphenyl]-3-propanoic acid(EAB 5151) in brain and blood microdialysate(online) and in plasma ultrafiltrate of freely moving rats. J.Chromatogr. B 679:167176

125. Tsai TH, Chen YF (2003) Pharmacokinetics of metronidazole in rat blood, brain and bile studied by microdialysis coupled to microbore liquid chromatography. J Chromatogr A 987: 277-282.

126. Luo D, Guo Y, Wang XY (2004) The corresponding problems and methods of the microdialysis correction. Lett Biotechnol 15:182.

127. Nandi P, Lunte SM (2009) Recent trends in microdialysis sampling integrated with conventional and microanalytical systems for monitoring biological events: a review. Anal Chim Acta 651: 1-14.

128. Pretti L, Bazzu G, Serra PA, Nieddu G (2014) A novel method for the determination of ascorbic acid and antioxidant capacity in Opuntia ficus indica using in vivo microdialysis. Food Chem 147: 131-137.

129. Mosetlha K, Torto N, Wibetoe G (2007) Determination of Cu and Ni in plants by microdialysis sampling: Comparison of dialyzable metal fractions with total metal content. Talanta 71: 766-770.

130. Steele KM, Lunte CE (1995) Microdialysis sampling coupled to on-line microbore liquid chromatography for pharmacokinetic studies. J Pharm Biomed Anal 13: 149-154.

131.Dan W (2009) The microdialysis technique coupled with the liquid chromatography establishment and in the application of the percutaneous pharmacokinetic study. Shanghai: Second Military Medical University:5.

132. Cheng FC, Kuo JS (1995) High-performance liquid chromatographic analysis with electrochemical detection of biogenic amines using microbore columns. J Chromatogr B Biomed Appl 665: 1-13.

133. McLaughlin KJ, Faibushevich AA, Lunte CE (2000) Microdialysis sampling with on-line microbore HPLC for the determination of tirapazamine and its reduced metabolites in rats. Analyst 125: 105-110. 
Citation: Lee MKK, Di L (2014) Crosstalk the Microdialysis in Scientific Research: from Principle to its Applications. Pharm Anal Acta 5: 276. doi: $10.4172 / 2153-2435.1000276$

134. Mathy FX, Vroman B, Ntivunwa D, De Winne AJ, Verbeeck RK, et al. (2003) On-line determination of fluconazole in blood and dermal rat microdialysates by microbore high-performance liquid chromatography. J Chromatogr B Analyt Technol Biomed Life Sci 787: 323-331.

135. Liu Y, Zhang J, Xu X, Zhao MK, Andrews AM, et al. (2010) Capillary ultrahigh performance liquid chromatography with elevated temperature for sub-one minute separations of basal serotonin in submicroliter brain microdialysate samples. Anal Chem 82: 9611-9616.

136. Yang FJ (1983) Microbore liquid chromatography. J High Resolut Chromatogr Commun 6: 348-358.

137. Verzele M (1984) Miniaturization of the particle size and low dispersion liquid chromatography: low viscosity solvent upward packing procedure. J Chromatogr 295:81-87.

138. Novotny M (1981) Microcolumns in liquid chromatography. Anal Chem 53:1294A-1308A

139. Krejci M, Kahle V(1987) New principle of sample introduction integrated with mobile phase delivery for microcolumn liquid chromatography. J Chromatogr 392: 133-142.

140. Trisciani A, Andreolini F (1990) Evaluation of micro-HPLC system dedicated to packed capillary column liquid chromatography. J High Resolut Chromatogr 13: $270-274$.

141. Chaurasia CS, Chen CE, Ashby CR Jr (1999) In vivo on-line HPLC microdialysis: simultaneous detection of monoamines and their metabolites in awake freely-moving rats. J Pharm Biomed Anal 19: 413-422.

142. Yoshitake T, lizuka R, Kehr J, Nohta H, Ishida J, et al. (2001) Determination of serotonin in microdialysis samples from rat brain by microbore column liquid chromatography with post-column derivatization and fluorescence detection. $J$ Neurosci Methods 109: 91-96.

143. Huang T, Shoup R, Kissinger $P$ (1990) A new microbore column for determination of dopamine, serotonin and other compounds in microdialysates. Curr Sep 9:139-143.

144.Andrén PE, Caprioli RM (1999) Determination of extracellular release of neurotensin in discrete rat brain regions utilizing in vivo microdialysis/ electrospray mass spectrometry. Brain Res 845: 123-129.

145. Shackman HM, Shou M, Cellar NA, Watson CJ, Kennedy RT (2007) Microdialysis coupled on-line to capillary liquid chromatography with tandem mass spectrometry for monitoring acetylcholine in vivo. $\mathrm{J}$ Neurosci Methods 159: 86-92.

146. Guihen E, Hogan AM, Glennon JD (2009) High-speed microchip electrophoresis method for the separation of (R,S)-naproxen. Chirality 21: 292-298.

147. Gao X C, Ma H W (2009) HPCE method to determine the monosaccharide composition of lilium brownii polysaccharides. J. Chinese Journal of experimental formulae of Chinese medicine 15:27.

148. Lapainis T, Sweedler J V (2008) Contributions of capillary electrophoresis to neuroscience. J Chromatogr A 1184:144-158

149. Hogan BL, Lunte SM, Stobaugh JF, Lunte CE (1994) On-line coupling of in vivo microdialysis sampling with capillary electrophoresis. Anal Chem 66: 596602.

150.Zhou SY, Zuo H, Stobaugh JF, Lunte CE, Lunte SM (1995) Continuous in vivo monitoring of amino acid neurotransmitters by microdialysis sampling with on-line derivatization and capillary electrophoresis separation. Anal Chem 67 594-599.

151. Zhou J, Heckert DM, Zuo H , Lunte CE, Lunte SM (1999) Online coupling of in vivo microdialysis with capillary electrophoresis/ electrochemistry. J Anal Chim Acta 379:307-317.

152. Lada MW, Vickroy TW, Kennedy RT (1997) High temporal resolution monitoring of glutamate and aspartate in vivo using microdialysis on-line with capillary electrophoresis with laser-induced fluorescence detection. Anal Chem 69: 4560-4565.
153. Bowser MT, Kennedy RT (2001) In vivo monitoring of amine neurotransmitters using microdialysis with on-line capillary electrophoresis. Electrophoresis 22 : 3668-3676.

154. Li Z, Zharikova A, Bastian J, Esperon L, Hebert N, et al. (2008) High tempora resolution of amino acid levels in rat nucleus accumbens during operan ethanol self-administration: involvement of elevated glycine in anticipation. $J$ Neurochem 106: 170-181.

155. Shou M, Ferrario CR, Schultz KN, Robinson TE, Kennedy RT (2006) Monitoring dopamine in vivo by microdialysis sampling and on-line CE-laserinduced fluorescence. Anal Chem 78: 6717-6725.

156. Rada P, Tucci S, Teneud L, Paez X, Perez J(1999) Monitoring gammaaminobutyric acid in human brain and plasma microdialysates using micella electrokinetic chromatography and laser- induced fluorescence detection. $J$ Chromatogr B Biomed Sci Appl 735:1-10

157.Park S, Lunte CE (1995) A perfluorosulfonated ionomer end-column electrical decoupler for capillary electrophoresis/electrochemical detection. Anal Chem 67: 4366-4370.

158. Qian J, Wu Y, Yang H, Michael AC (1999) An integrated decoupler for capillary electrophoresis with electrochemical detection: application to analysis of brain microdialysate. Anal Chem 71: 4486-4492.

159. Takada Y, Yoshida M, Sakairi M, Koizumi H (1995) Detection of gammaaminobutyric acid in a living rat brain using in vivo microdialysis-capillary electrophoresis/mass spectrometry. Rapid Commun Mass Spectrom 9: 895896.

160.Zhang H, Stoeckli M, Andren PE, Caprioli RM(1999) Combining solid-phase preconcentration, capillary electropherosis and off-line matrix-assisted lase desorption/ionization mass spectrometry:intracerebral metabolic processing of peptide E in vivo. J Mass Spectrom34: 377-383.

161. Huynh BH, Fogarty BA, Martin RS, Lunte SM (2004) On-line coupling of microdialysis sampling with microchip-based capillary electrophoresis. Anal Chem 76: 6440-6447.

162. Sandlin ZD, Shou M, Shackman JG, Kennedy RT (2005) Microfluidic electrophoresis chip coupled to microdialysis for in vivo monitoring of amino acid neurotransmitters. Anal Chem 77: 7702-7708.

163. Yao T, Okano G (2008) Simultaneous determination of L-glutamate, acetylcholine and dopamine in rat brain by a flow-injection biosensor system with microdialysis sampling. Anal Sci 24: 1469-1473.

164.Zilkha E, Obrenovitch TP, Koshy A Kusakabe H, Bennetto HP (1995) Extracellular glutamate: on-line monitoring using microdialysis coupled to enzyme-amperometric analysis. J Neurosci Methods 60: 1-9.

165. Volpe G, Moscone D, Compagnone D, Palleschi G (1995) In vivo continuous monitoring of L-lactate coupling subcutaneous microdialysis and an electrochemical biocell. Sensors Actuators B 24:138-141.

166. Sun X F, Wang DX (2011)Shouwu Fang and the outer fluid dynamics affect the pharmacokinetics of levodopa in Parkinson's disease rat model of blood cells in the striatum study. J Chinese Journal of experimental formulae of Chinese medicine, $17: 111$. 